\title{
Critical Care Nutrition: Getting Involved as a Gastrointestinal Endoscopist
}

\author{
Stephen A. McClave, MD
}

\begin{abstract}
The route, timing, and volume of enteral feeding delivered to a patient in the intensive care unit have a profound effect on clinical outcome. At the height of critical illness, problems with ileus, aspiration, and the systemic inflammatory response syndrome make the provision of enteral nutrients a difficult and somewhat risky endeavor. The gastrointestinal endoscopist has the technical skills to place feeding tubes deep within the jejunum and an underlying expertise in gut physiology to monitor patients effectively once feeds are initiated. Attention to detail in the techniques for attaining enteral access, early identification of potential problems, and quick institution of simple endoscopic strategies help improve delivery of nutrition support, minimize the likelihood for inhospital complications, and optimize patient outcome.
\end{abstract}

Key Words: enteral feeding, enteral nutrition, enteral access, feeding tubes, gut immunology

( Clin Gastroenterol 2006;40:870-890)

U until 10 years ago clinicians regarded nutrition as "a soft science." Much of what was done in clinical practice was based on poorly controlled, mostly retrospective data and expert opinion. Getting physicians to change practice was difficult, as recommendations from nutrition support specialists were supported by a paucity of data.

Over the past decade however, a new problem has arisen. We now have a large volume of prospective randomized controlled trials in clinical nutrition that have helped clarify which issues are important and which concepts from the past now represent dogma and should be discarded. The problem relates to the fact that physicians have trouble believing the data from these prospective randomized trials. These studies indicate that achieving enteral access and providing enteral nutrition (EN) seem to have a profound effect on the course of the disease process and ultimate patient outcome. Physicians lose sight of the fact that the gut is the largest immune organ in the body and that the timing, volume, and

From the Department of Medicine, University of Louisville School of Medicine, Louisville, KY

Reprints: Stephen A. McClave, MD, Division of Gastroenterology/ Hepatology, University of Louisville School of Medicine, Louisville, KY 40202 (e-mail: Stephen.McClave@louisville.edu).

Copyright (c) 2006 by Lippincott Williams \& Wilkins content of feeds which are infused into the lumen of the gut can have a tremendous impact on the level of oxidative stress, the tone of systemic immunity, and the likelihood for complications. ${ }^{1-3}$

The data on the benefits of EN are so strong that multidisciplinary nutrition support teams are under pressure to establish enteral access and get feedings initiated. Such teams are desperate for the services of the gastrointestinal endoscopist with underlying expertise in physiology of the gut and the skills to establish deep jejunal access. This paper will review the evidence for the value of enteral feeding in critical care, describe the endoscopic techniques for achieving deep jejunal access, and discuss the most common complications and problems encountered in monitoring and providing EN to the critically ill patient.

\section{WHY ENTERAL NUTRITION IS IMPORTANT}

Recently, there has been a paradigm shift in our perspective of the role of the gut in critical illness. In the past, we thought of the gut as a passive organ. With an overall pattern of reduced motility, clinicians let "sleeping dogs lie" and did not consider using the gut until the height of critical illness had passed. If there was concern for dysfunction of the gut, it was focused on stress gastropathy, bleeding in the intensive care unit (ICU), ileus, and whether or not parenteral nutrition (PN) should be initiated. Concern for multiple organ failure syndrome seemed to focus on what was considered to be the "vital organs," like the lungs, heart, and the kidney. Evidence now suggests that with gut disuse in critical illness, the gastrointestinal (GI) tract becomes a dynamic organ and "roars like a lion." 3,4 Concern for gut dysfunction now focuses on increases in permeability, increased engagement of luminal bacteria with the immune system, and an upregulation of systemic immunity. ${ }^{3-5}$ Now when clinicians consider multiple organ failure syndrome, there is increasing concern for gut failure. When the gut fails, it becomes a proinflammatory organ, contributing immune mediators to the systemic milieu and adding its own component to the systemic inflammatory response syndrome. Failure of the gut can lead to failure of other organs, such as the lungs, kidney, and the liver..$^{3-6}$

With this paradigm shift of perspective as to the role of the gut in critical illness, our priorities of nutritional management have changed as well. Early on, after admission to the ICU, the major priority of providing 
EN is to attenuate oxidative stress and modulate systemic immunity. A fairly narrow window of opportunity exists (somewhere up through the first 2 to $4 \mathrm{~d}$ of admission) by which EN can set the tone for the immune response. 7 After this point in time, the ability to further modulate the immune system diminishes, as the "die is cast." Although there seems to be a dose-dependent effect and a certain volume required to achieve this effect from $\mathrm{EN},{ }^{9}$ exactly meeting calorie and protein requirements early on in the first week of hospitalization is of low priority. Eventually by the seventh or eighth day of hospitalization, failure to meet protein and calorie requirements at this point in time contributes to deterioration of nutritional status, which may begin to exert a deleterious effect on systemic immunity. ${ }^{1,10}$

Such a "window of opportunity" for the clinical benefits of EN is not a myth. This concept is now supported by over 15 prospective randomized trials and 2 meta-analyses. ${ }^{8,11}$ These 2 recent meta-analyses summarize studies comparing early (feeds initiated within $36 \mathrm{~h}$ ) versus delayed (initiated after $36 \mathrm{~h}$ ) feeding have shown a reduction in infection by $55 \%(P=0.0006)$, shortened hospital length of stay by 2.2 days $(P=0.0004)$, and a reduction in mortality by $48 \%(P=0.08)$ with use of early EN compared to delayed feeds. ${ }^{8,11}$ These data suggest that provision of EN is a primary therapeutic strategy that may be just as important as provision of a pharmacologic agent or initiation of supportive therapy for organ failure (such as dialysis and mechanical ventilation).

A variety of mechanisms are involved in the beneficial effect of EN. Provision of EN maintains gut integrity and keeps the intercellular channels between the epithelial cells of the gut closed ${ }^{12}$ (Fig. 1). As a dynamic process, these channels have a tendency to open in response to clinical insult. Evidence suggests that it is much harder to get the channels to close once they are open, than to prevent them from opening in the first place (Fig. 1). Feeding stimulates the release of bile salts and secretory $\operatorname{IgA}$, which tend to coat bacteria within the lumen of the gut. ${ }^{13}$ Bacteria need to adhere to the intestinal wall before they can engage the immune system. By coating the bacteria and stimulating peristalsis with

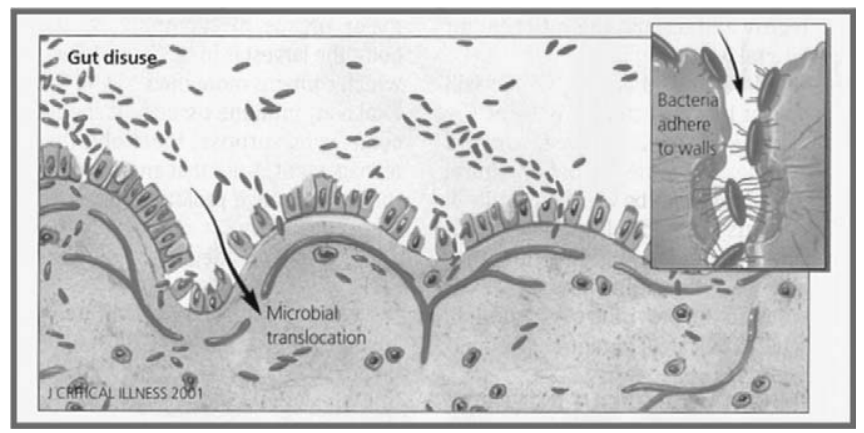

FIGURE 1. Loss of gut integrity resulting in increased gut permeability. Reproduced with permission from / Crit Illness 2001;16:198.
$\mathrm{EN}$, the overall numbers of bacteria are kept in check. ${ }^{12}$ Feeding also stimulates blood flow to the gut, which helps prevent ischemia/reperfusion injury. Provision of EN supports the role of commensal bacteria. When a baby is born, the gut is sterile and becomes colonized over the first month of life. The gut-associated lymphoid tissue (GALT) develops over the first 6 months of life. The fact that these processes develop simultaneously may be one reason why there is tolerance of the immune system for these commensal bacteria. Such bacteria provide both direct and indirect protection for the host. The colonization by commensal bacteria provides indirect protection by preventing colonization of pathogenic bacteria such as Pseudomonas. Direct protection is provided by organisms such as Escherichia coli, that produce a disaccharidase enzyme that breaks down the toxin produced by Pseudomonas. ${ }^{14}$ Alverdy ${ }^{14}$ has shown that bacteria in the gut can sense decreases in $\mathrm{pH}$ or oxygen levels as the host goes into shock, and in response switch on virulence genes. When these genes are expressed, the bacteria go into an adherent phase, attach to the intestinal wall, and cause a contact-dependent activation of the intestinal epithelial cells (IECs). ${ }^{14}$ Such activation causes these cells to become immune active cells and begin releasing cytokines. The cytokines in turn activate neutrophils that are flowing through the splanchnic circulation of the gut. ${ }^{15}$ Tremendous increases in permeability occur because of opening of the tight junctions between the IECs. Programmed apoptosis of these cells occurs which leads to further larger defects in the barrier defense system of the gut (Fig. 1). In an animal model, Alverdy ${ }^{14}$ has shown that the number and type of bacteria colonizing the gut at the time the host goes into shock determines the degree of the inflammatory response generated by the gut. Progressing from a normal number of commensal bacteria, to bacterial overgrowth of commensal bacteria, to bacterial overgrowth of pathogenic organisms (a sequence which would occur naturally in response to failure to use the gut in critical illness), there is a steady increase in the volume of cytokines (tumor necrosis factor and interleukin-6) that are released from the gut. ${ }^{14}$ This effect of EN on commensal bacteria is the basis for the tremendous potential of probiotic therapy in critical care.

EN maintains the mass of GALT and mucosalassociated lymphoid tissue (MALT) at distant sites throughout the body ${ }^{10}$ (Fig. 2). As the largest immune organ in the body, the gut is responsible for producing over $80 \%$ of immunoglobulin secretory-IgA. ${ }^{16}$ Clinicians may think of the gut as the center where lymphocytes are "educated." The gut functions like a factory producing secretory-IgA immunocytes (B-cells and plasma cells) that go out to distant sites such as the respiratory bronchi (bronchial-associated lymphoid tissue), ${ }^{10,17}$ the adenoid and nasal passages (nasal-associated lymphoid tissue), and the tonsils (tonsilar-associated lymphoid tissue) (Fig. 2). In humans, failure to use the gut can result in a decrease by as much as $50 \%$ in the mass of secretory-IgA producing immunocytes within 2 to 11 days of major surgery. ${ }^{18}$ In an animal model, Kudsk has shown that loss of GALT tissue 
affects viral clearance and subsequent pneumonia at the level of the lung. ${ }^{10,19}$ After a major injury, failure to use the gut causes reductions in secretory-IgA produced at the level of the lung, increasing susceptibility to viral pneumonia. Reinstituting EN restores pulmonary secretory-IgA levels back to normal and clearance of the virus from the alveolar spaces improves. ${ }^{10,19}$ Although these specific steps have not been documented in humans, the most consistent outcome effect improved with provision of EN in critically ill patients as a reduction in infection, most often of which is nosocomial pneumonia. ${ }^{1,8,20}$

Failure to use the gut causes increases in gut permeability, a phenomenon which is time-dependent and which correlates to increasing disease severity ${ }^{12,21}$ (Fig. 1). The time-dependent characteristic of increased gut permeability was shown in a study from Taiwan in burn patients who were randomized to early enteral feeding (initiated within $24 \mathrm{~h}$ of admission) or delayed feeding (initiated after $48 \mathrm{~h}$ ). ${ }^{7}$ Increases in gut permeability were seen in the delayed group by the 24-hour mark (compared to the early group), a difference which continued throughout the remaining 4 days of the study. By the 7 to 12-hour mark, systemic levels of endotoxin and tumor necrosis factor were significantly higher in the delayed feeding group compared to the early group, differences again which remained significantly higher throughout the 5 days of the study. Correlation of increased gut permeability to disease severity was shown in patients with pancreatitis using polyethylene glycol as a marker of gut permeability. ${ }^{21}$ Patients with mild pancreatitis had permeability markers no different than controls with no pancreatitis. Patients with severe pancreatitis but an otherwise uncomplicated course had a 4-fold increase in permeability, whereas those patients with severe pancreatitis complicated by organ failure had another 4-fold increase in permeability above that. ${ }^{21}$

The clinical consequences of increased permeability are risk of systemic infection and risk of organ failure. ${ }^{5,7,9}$ In burn patients, Ziegler $^{9}$ showed in a prospective study that those burn patients who remained uninfected throughout hospitalization had permeability indices (as measured by lactose/mannitol ratios) that were no different from controls with no burns. Those burn patients who became infected demonstrated a 3-fold increase in gut permeability. ${ }^{9}$ In a prospective study by Doig, ${ }^{5} 37$ patients admitted to the ICU were evaluated, 28 of whom developed organ failure. ${ }^{5}$ The risk and the severity of either primary organ failure (present on admission) or secondary organ failure (developed over the first week of ICU admission) correlated to abnormalities of intestinal permeability on admission $(P<0.01){ }^{5}$

In the past, clinicians focused on the concept of bacteria translocation, and had the misconception that bacteria could pass out of the GI tract with increases in permeability and migrate to distant sites such as the lungs. A study by Moore, however, showed that routine cultures in the portal vein in surgical critical care were routinely negative. ${ }^{22}$ More recent data suggest that lymphatic channels act as a conduit for inflammatory mediators exiting the gut. ${ }^{6}$ When bacterial antigen engage IECs and macrophages at the level of the gut, cytokines and activated neutrophils are released into lymphatic channels. These lymphatic channels lead into the thoratic duct, to the left subclavian vein, into the heart, and out into the pulmonary artery. As a result, the first capillary bed that is reached by these cytokines after their exit from the gut is located in the lungs. ${ }^{6}$ Accumulation of inflammatory cytokines and sequestration of activated neutrophils in the alveoli lead to increases in endothelial permeability, a process which serves as the mechanism of injury causing pneumonia and adult respiratory distress syndrome. $^{6}$ In an animal model, ligating the lymphatic duct protects against lung injury after hemorrhagic shock. ${ }^{6}$ Such mechanisms show the close relationship between events of the gut, maintenance of gut integrity, and susceptibility to pulmonary injury.

Whether or not the critically ill patient is fed by the enteral route affects both the innate and acquired immune response. $^{23}$ Failure to provide EN stimulates macrophages of the innate immune response, a process which occurs over several hours and is caused by either ischemia/reperfusion injury or increased engagement of bacteria with these cells (because of increased permeability). ${ }^{23}$ Once macrophages are activated, neutrophils passing through the splanchnic circulation of the gut become primed by these cells and pass out to distant sites such as the lungs, liver, and the kidney. ${ }^{3,15}$ The occurrence of a second insult (such as hypotension or hypoxemia) may lead to the activation of these primed neutrophils and their subsequent passage out of the vascular space into the organ tissue itself, a process which ultimately leads to increased oxidative stress and organ failure. ${ }^{3}$

Whether or not the critically ill patient receives $\mathrm{EN}$ helps "set the tone" for the acquired immune response, a process which occurs over 3 to 5 days and involves proliferation of a defined population of lymphocytes 3,24 (Fig. 3). Dendritic macrophages, which are professional antigen-presenting cells, continuously sample the luminal contents within the gut. ${ }^{24}$ If the patient has been receiving EN, the dendritic macrophage "senses" a normal number of commensal bacteria and food antigen, which results in the release of interleukin- 4 by the cell. ${ }^{18,25}$ In contrast, in a setting of gut disuse, the same dendritic macrophage samples or "senses" bacterial overgrowth of pathogenic bacteria and an absence of food antigen present, and as a result interleukin-12 is released. ${ }^{25,26}$ After the sampling of the luminal contents, the dendritic macrophage migrates back down into the lamina propria where there is a bed of naive CD-4 helper T-lymphocytes ${ }^{18}$ (Fig. 3). In response to gut disuse and the release of interleukin-12, these naive lymphocytes proceed down a $\mathrm{T}_{\mathrm{H}} 1$ pathway, which is proinflammatory, and go on to produce interferon- $\Gamma$ and tumor necrosis factor- $\beta .^{10}$ In a setting of enteral feeding and the release of interleukin-4, in contrast, the same cells proceed down a $\mathrm{T}_{\mathrm{H}} 2$ pathway, which down-regulates systemic immunity and directly opposes the proinflammatory $T_{\mathrm{H}} 1$ pathway. In response to interleukin-4, 


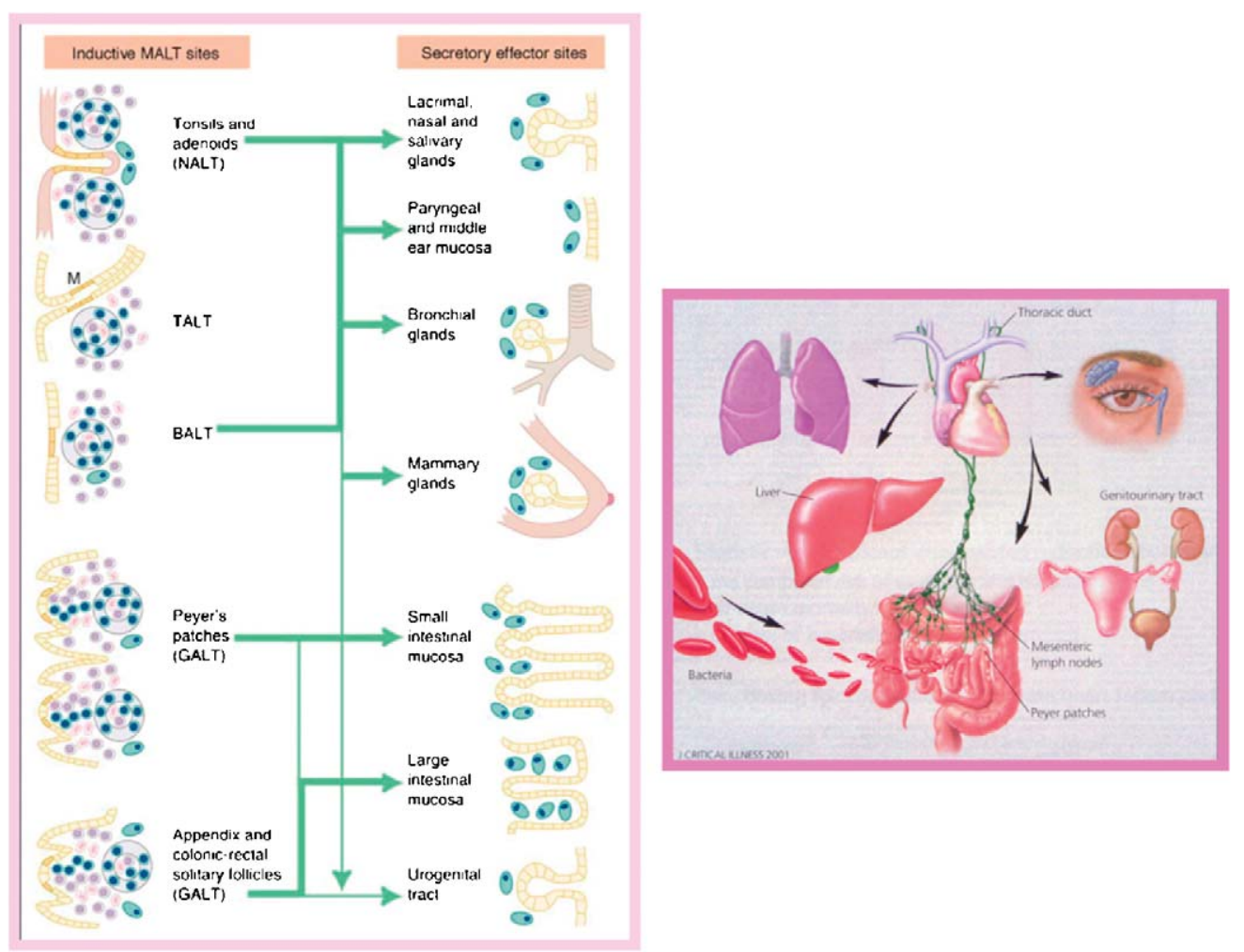

FIGURE 2. Maintenance of GALT and MALT at distant sites. Reproduced with permission from Immunol Today 1999;20:267-277 and from Ann Intern Med 1987;106:853-870.

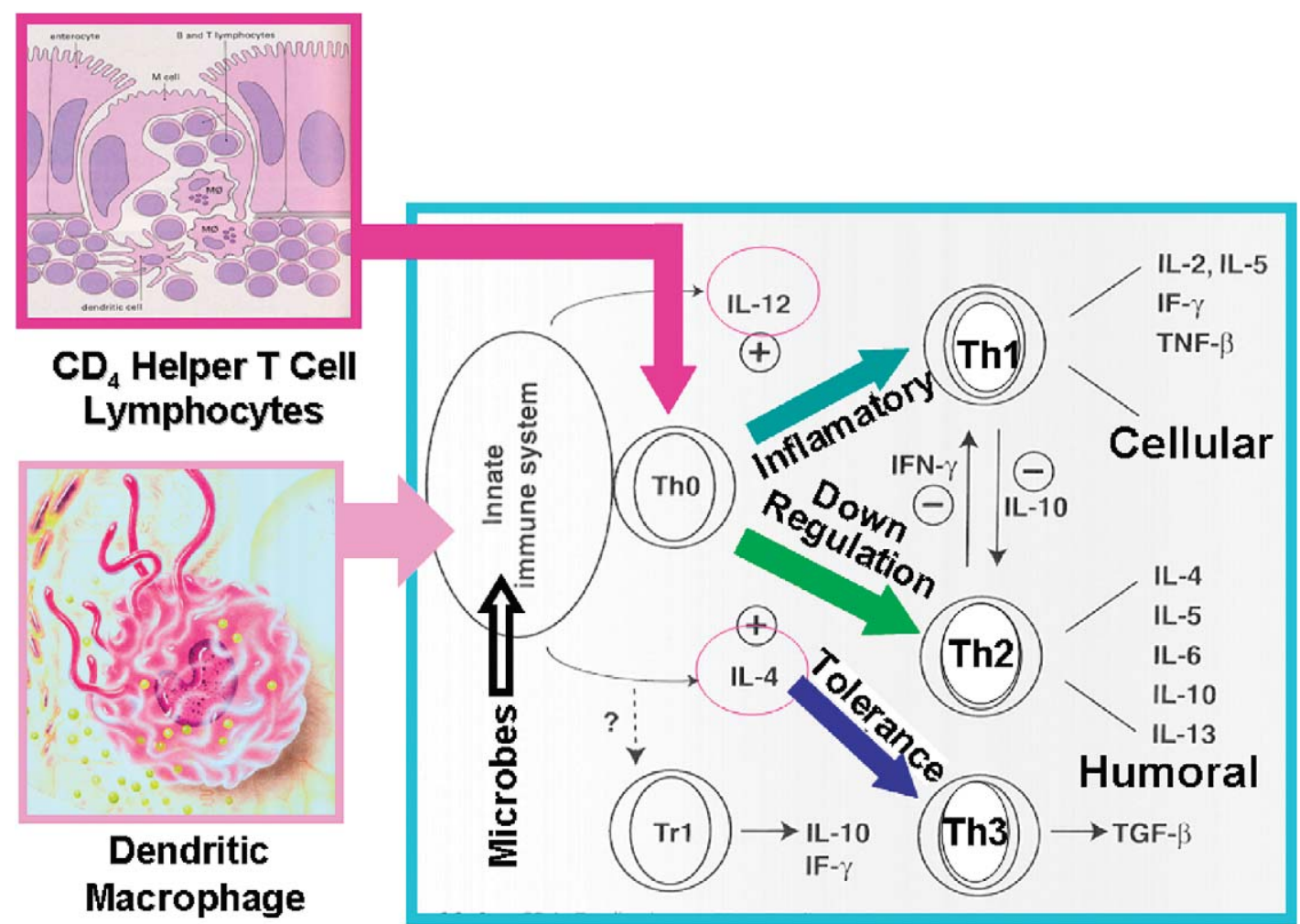

FIGURE 3. Effect of feeding versus gut disuse on setting the tone for the acquired systemic immune response. Reproduced with permission from Immunol Today 1999;20:267-277. 
additional pathways ( $\mathrm{Tr}-1$ and $\mathrm{T}_{\mathrm{H}} 3$ ) involved in oral tolerance are stimulated and a proliferation of these cells go on to produce the cytokine transforming growth factor- $\beta .^{25,27}$ This latter cytokine is so good at reducing inflammation at the level of the gut, that it is being used in formulas to treat patients with Crohn disease. The overall effect of the stimulation of $\mathrm{T}_{\mathrm{H}} 2, \mathrm{Tr}-1$, and $\mathrm{T}_{\mathrm{H}} 3$ pathways is to down-regulate systemic immunity and reduce overall inflammation, an effect which spills over into the systemic circulation $^{25}$ (Fig. 3).

EN also affects the role of adhesion molecules. ${ }^{28}$ For cells to exit a vascular space and enter a particular tissue, adhesion molecules have to be expressed on the surface of the cell and the lining of the vascular space. Attraction between these adhesion molecules allows the cells to slow down, attach to the wall, and then diapedese across and into the tissue. ${ }^{28}$ Neutrophils which have been initially activated at the level of the gut and then are subsequently passing through the pulmonary circulation, require expression of intercellular adhesion molecule and E-selectin adhesion molecules to pass out into the pulmonary tissue. ${ }^{29}$ Gut disuse resulting in decreases in $\mathrm{T}_{\mathrm{H}} 2$ cytokines, cause an up-regulation of these adhesion molecules, which effectively opens the door for these neutrophils to pass out into the alveoli tissue. ${ }^{29}$ In contrast, GALT cells which are homing back to the gut to provide protection against luminal bacteria require the expression of mucosal addressin cellular adhesion molecule to pass out of the vascular space and into the lamina propria of the gut. ${ }^{10,26}$ With gut disuse and decreases in the $\mathrm{T}_{\mathrm{H}} 2$ cytokines, there is down-regulation of mucosal addressin cellular adhesion molecule levels, an effect which essentially closes the door to these GALT cells and prevents their exiting from the vascular space. ${ }^{10,26}$

The impact of these physiologic processes is well documented in clinical studies. The differential effect of feeding versus starvation on level of oxidative stress is demonstrated in a study by Fong ${ }^{30}$ in normal, healthy volunteers. Volunteers were randomized to receive EN or PN for 7 days, after which femoral artery and venous access was established and subjects were challenged with intravenous $E$. coli endotoxin. Systemic levels of glucagon, tumor necrosis factor, and epinephrine were significantly greater in the subjects randomized to $\mathrm{PN}$ compared to those receiving $\mathrm{EN}$, after infusion of the E. coli endotoxin. ${ }^{30}$ Protein flux was more negative in the group randomized to $\mathrm{PN}$, indicating greater muscle catabolism compared to the group randomized to $\mathrm{EN}$. Thus, in humans with the same laboratory insult, gut disuse with PN potentiated the stress response compared to those patients randomized to EN. ${ }^{30}$ This differential effect of starvation versus feeding has a profound effect on clinical outcome. The greatest volume of data demonstrating these effects are seen in those studies in which patients are randomized to $\mathrm{EN}$ or PN. In recent meta-analyses by Braunschweig and Heyland, ${ }^{1,20}$ the most consistent effect from EN compared to $\mathrm{PN}$ is a reduction in septic morbidity by $27 \%$ to $34 \%$. Overall complications and hospital length of stay are also reduced significantly with usage of the gut. ${ }^{1,20}$ But this effect cannot be attributed to a deleterious effect of $\mathrm{PN}$, as an increasing number of studies are now seen comparing EN with no nutritional support. In a meta-analysis by Lewis in surgical critical care, use of EN was shown to reduce infection by $28 \%$ and hospital length of stay by 0.84 days $(P=0.001)$, compared to patients receiving "standard therapy" with no specialized nutritional support. ${ }^{2}$

The effect of EN on outcome may be potentiated by the addition of immune-modulating agents to the enteral formula. Addition of direct immune stimulants such as arginine, and RNA nucleotides conceivably may help stimulate proliferation of lymphocytes involved in the down-regulatory $\mathrm{T}_{\mathrm{H}} 2$ pathways. ${ }^{31}$ Substituting borage oil or omega-3 fish oils for traditional omega-6 fatty acid, alters the phospholipids in cell membranes of immune active cells. When such cells as macrophages, lymphocytes, and activated neutrophils proceed to oxidative burst, the leukotrienes, prostaglandins, and thromboxanes generated by the arachidonic acid cascade from these substituted fats have one-tenth the biologic activity as similar agents generated from omega- 6 fatty acid. ${ }^{32,33}$ As a result, the overall level of inflammation is reduced. The addition of antioxidants such as vitamin $\mathrm{C}$, vitamin $\mathrm{E}$, selenium, and glutamine help reduce the overall levels of oxidative stress as well. In a recent meta-analysis of 26 studies, Montejo ${ }^{34}$ showed that for patients receiving immune-modulating formulas, infections (nosocomial pneumonia, wound infections, and interabdominal abscesses) were reduced from $46 \%$ to $54 \%$, organ failure was reduced by $79 \%$, and the time spent on mechanical ventilation, in the ICU, and in the hospital was reduced from 1.6 to 3.4 days, compared to those patients receiving standard EN formulas (all differences $P<0.001$ ).

These clinical studies showing the profound effect of EN on outcome in the critically ill patient indicates that nutrition therapy is no longer adjunctive, supportive care. Achieving enteral access and providing EN represents a proactive, primary therapeutic strategy which needs to be initiated very early after admission to the ICU to achieve the clinical benefits. Such therapy requires expertise in techniques for enteral access and participation by physicians who are knowledgeable in monitoring gut physiology.

\section{ACHIEVING ENTERAL ACCESS}

For the majority of cases, enteral access may be achieved simply and easily by placing a nasogastric tube and initiating EN immediately after volume resuscitation and attainment of hemodynamic stability. As multidisciplinary nutrition teams become more aggressive in feeding the critically ill patient however, problems with ileus and patients at high risk for aspiration increasingly require postpyloric feeding. Small bowel feeding requires a greater degree of expertise, a factor which may lead to delays in initiation of EN. Postpyloric feeding may be more successful in a patient prone to ileus, may reduce risk of aspiration pneumonia, and is more likely to achieve goal rate of feeding when compared to gastric feeds. ${ }^{35}$ 
Thus, when the multidisciplinary nutrition team calls on the services of a gastrointestinal endoscopist, most often the request is for deep jejunal access. Having the expertise to come to the ICU and place tubes into the jejunum endoscopically without fluoroscopic guidance avoids the problems encountered by the blinded bedside technique (which is time consuming and poorly tolerated), exposure to radiation involved with fluoroscopic techniques, and the risk for aspiration pneumonia and transport mishaps that occur if the patient has to be transported down to the radiology suite for fluoroscopic placement. ${ }^{36}$

\section{Endoscopic Nasoenteric Tube}

When achieving deep jejunal access, an important maxim of strategy is to "drag wires not tubes." Grabbing a string on the end of a feeding tube with biopsy forceps and attempting to drag that with the endoscope through the stomach into the small bowel is a highly frustrating experience. The large tube tends to obscure endoscopic visualization, dragging the tube with the scope makes for clumsy handling of the scope, and the likelihood for displacing the tube when the scope is withdrawn is very high. In contrast, dragging a wire into place with biopsy forceps, withdrawing the scope back to a neutral position, and then inserting a tube over a wire is much easier and less frustrating for the operator. Further advice in the management of an effective "tube service," is to use a pediatric colonoscope, which is stiffer than a small bowel enteroscope, and of greater length than a gastroscope for getting tubes well below the Ligament of Treitz. Specifically for endoscopic nasoenteric tube (ENET) placement, the guidewire must be as long as twice the length of the endoscope plus 20 to $30 \mathrm{~cm}$. As a result, guidewires usually have to be well over $250 \mathrm{~cm}$ in length. The guidewires provided with most nasoenteric tubes are not long enough. A standard 0.035 gauge wire, $480 \mathrm{~cm}$ in length, is an inexpensive reliable wire for deep jejunal placement.
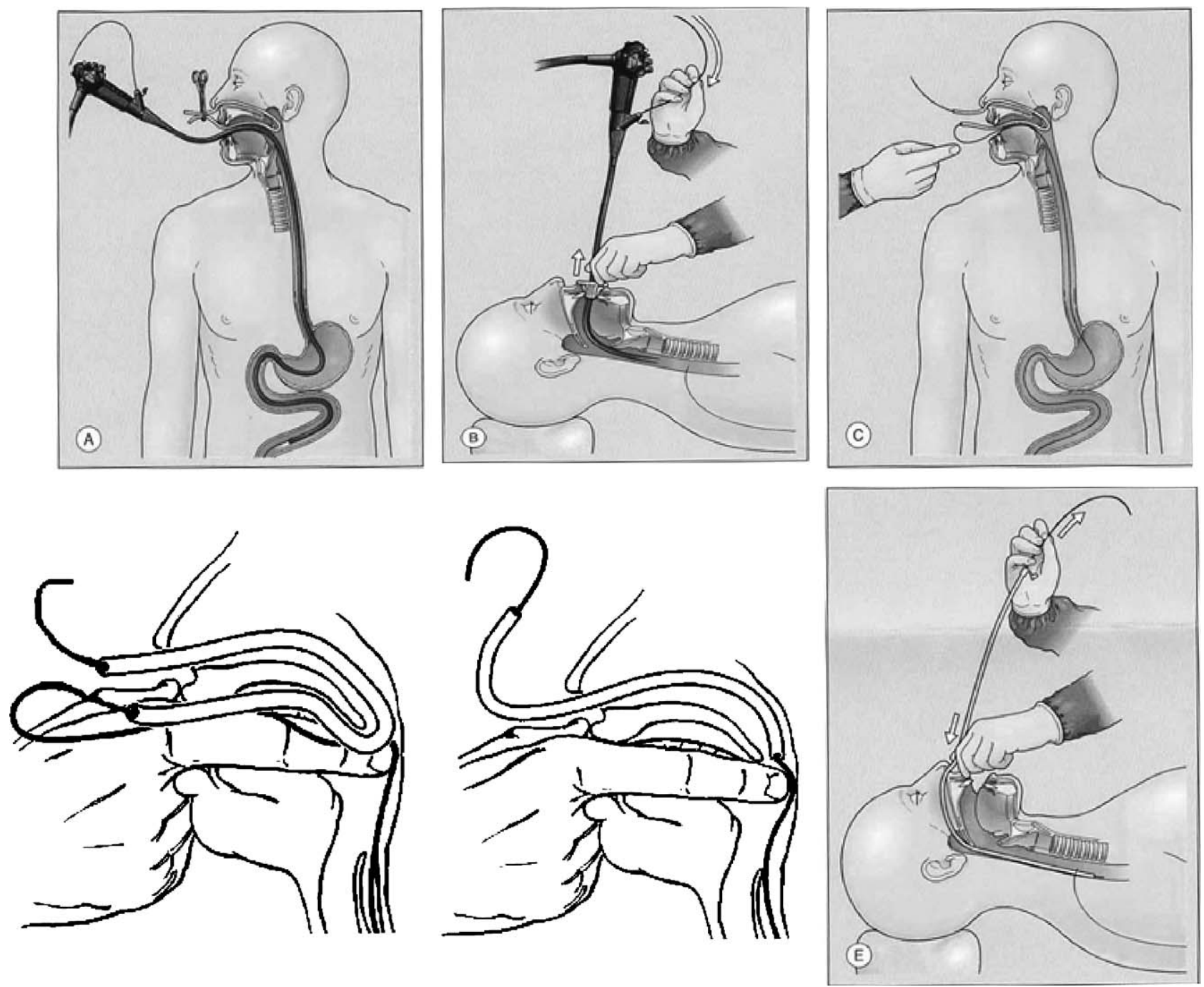

FIGURE 4. Over the guidewire technique for ENET placement. Reproduced with permission from Clinical Gastrointestinal Endoscopy. Ginsberg GG, et al, eds; 2005:351-356 and from Tech Gastroint Endosc 2001;3:26. 
The most reliable method for ENET placement is the "Over the Guidewire Technique" (Fig. 4). Before passing the endoscope, an oronasal transfer tube is placed through the nares and brought out through the mouth. A pediatric colonoscope is then passed through the mouth, down through the esophagus, stomach, into the small bowel and proximal jejunum, hopefully 2 to 3 loops below the Ligament of Treitz. The guidewire is passed out further (as far as possible) and then the scope is withdrawn off the wire. The trick to keeping the tip of the wire in place is to withdraw the scope with one hand while the other hand of the endoscopist is on the guidewire exiting the operating channel of the scope. The scope is withdrawn $1 \mathrm{~cm}$ at a time as the wire is passed simultaneously $1 \mathrm{~cm}$ through the operating channel. Transfer of the wire through the oronasal transfer tube and out the nose is facilitated by reaching in alongside the bite block and pressing the wire against the posterior hypopharynx. The end of the wire exiting the nose is pulled out until the wire along the posterior wall of the hypopharynx is straight, descending the posterior oropharynx down into the esophagus. The feeding tube is then placed over the guidewire, again using a 1:1 ratio in which the tube is passed $1 \mathrm{~cm}$ through the mouth as the wire exits the tube at the proximal end by $1 \mathrm{~cm}$. The endoscopist always has one hand on the tube and the other hand on the wire exiting the feeding tube while assistants support the weight of the tube in the middle (Fig. 4).

An alternate, but equally effective method, is the "Transnasal Technique" (Fig. 5). With this method, a $5.5-\mathrm{mm}$ neonatal gastroscope is passed through the nares down into the esophagus through the stomach and on into the small bowel. The secret to this technique is stiffening the scope with a small biopsy forceps or the spring-tip guidewire from the Savory dilation system. Usually the scope can be passed just proximal or immediately distal to the Ligament of Treitz, but the wire can be passed out further beyond the tip of the endoscope. The scope is then withdrawn off the wire and the feeding tube is passed over the wire into position (Fig. 5). It is important at this point to pass the scope down the other nares into the stomach to check the position of the tube and confirm that the tube is not looped in the stomach.

Further alternative methods for ENET placement include variations of the "Drag and Pull Technique" (Fig. 6). In one version, 2 guidewires are placed in the feeding tube and then passed into the stomach. The scope is then passed through the mouth into the stomach and one wire is pushed out beyond the end of the feeding tube. With the endoscope and biopsy forceps, the tip of the wire is grabbed and dragged down into the small bowel. The biopsy forceps are pushed out further into the small bowel while the scope is withdrawn back into the stomach. At that point, the operator pushes the feeding tube down over the guidewire that is down in the small bowel into final position. The two guidewires cause the tube to be stiff enough to allow the endoscope to be withdrawn and removed out from the mouth. Only after

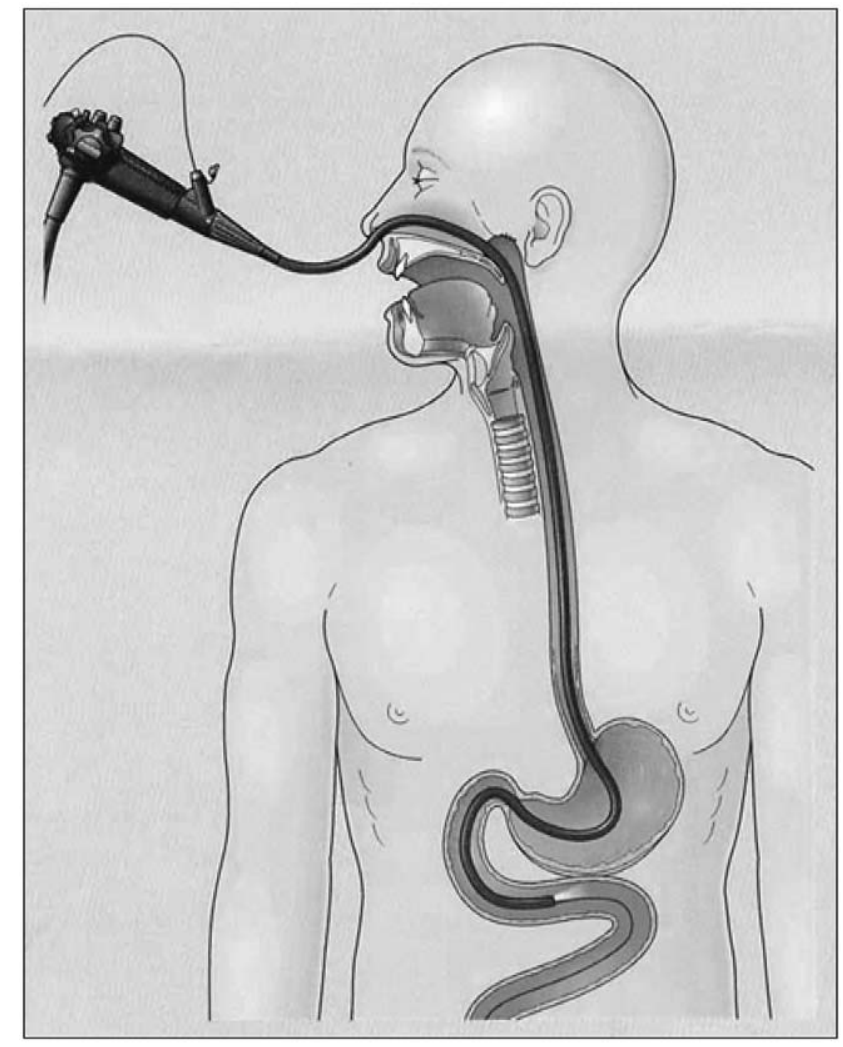

FIGURE 5. Transnasal technique for ENET placement. Reproduced with permission from Clinical Gastrointestinal Endoscopy. Ginsberg GG, et al, eds; 2005:351-356.

the scope has been withdrawn completely are the guidewires removed from the feeding tube (Fig. 6).

In a second version of the "Drag and Pull Technique," 3 guidewires are placed in the feeding tube, which is then passed into the stomach through the nares (Fig. 7). The endoscope is passed into the stomach and biopsy forceps are used to push the tip of this stiffened feeding tube through the pylorus into the proximal duodenum. With 3 guidewires in place, the tube is stiff enough now to pass the tube manually at the level of the nose and allow the tip to migrate down through the duodenal c-loop closer to the Ligament of Treitz. Once the tube seems to be in position and the endoscopic view from the stomach confirms that no loop is present, the endoscope is withdrawn before removing the 3 guidewires (Fig. 7).

Any time an endoscopist is requested to place an ENET tube, the tube should be secured with a nasal bridle (Fig. 8). Usually this is done before endoscopy, before the oronasal transfer tube is placed. A 5-French neonatal feeding tube, which essentially looks like a plastic wire in the hands of the operator, is placed through the nares and brought out the mouth (Fig. 8). A second similar tube is placed through the other nares and brought out the mouth, after which the ends protruding from the mouth are sutured together. Traction is applied to one of the tubes exiting from the nares 

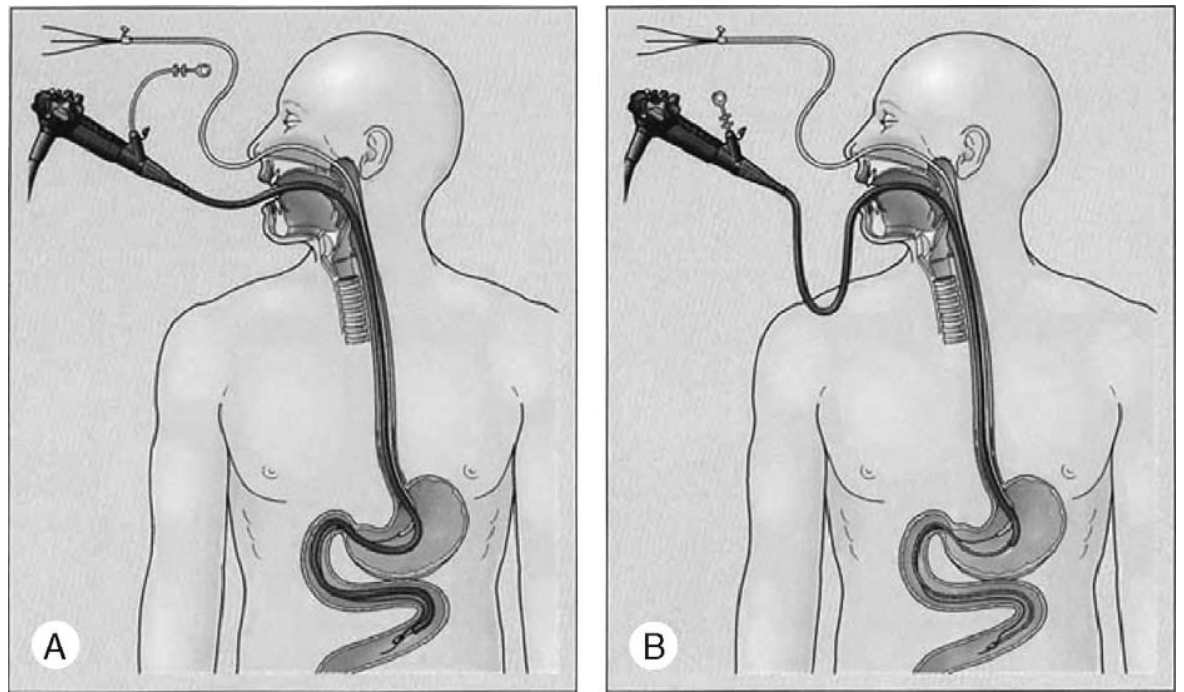

FIGURE 6. Variation of Drag and Pull technique for ENET placement. Reproduced with permission from Clinical Gastrointestinal Endoscopy. Ginsberg GG, et al, eds; 2005:351-356.

pulling the bridle into final position (in one nares, around the nasal septum, and out the other nares). The ENET tube is then placed as described earlier. Once in final position, the tube is taped to the bridle, beginning $1 \mathrm{~cm}$ below the nose (Fig. 8). Use of such a nasal bridle has been shown in a prospective randomized trial to reduce displacement from $38 \%$ down to $4 \%$ (CPB99).

\section{Percutaneous Endoscopic Gastrostomy Placement}

Most gastrointestinal endoscopists are familiar with routine percutaneous endoscopic gastrostomy (PEG) placement by either the "Ponsky Pull Technique" or the "Sacks-Vine Push Technique",37,38 (Fig. 9). It is important in the ICU setting, however, to alter the position for initial placement in anticipation of patient intolerance. Traditional positioning for PEG tubes is located on the patient's left side in the vortex formed by the left costal margin and the midline linea alba. This position results in a longer, more tangential route into the proximal stomach. Shifting to the right of the midline down closer to the umbilicus creates a pathway that is shorter and more perpendicular into the stomach, and positions the feeding tube in the antrum closer to the pylorus. If shortly after PEG placement, the patient is found to be intolerant of gastric feeding and conversion of the PEG to a percutaneous endoscopic gastrojejunostomy (PEGJ) is required, this change in placement site facilitates such a conversion.

It is very important at the conclusion of PEG placement to visually inspect and confirm that the internal bolster has been positioned gently against the mucosal wall. The external bolster is then set at the patient's abdominal wall, such that there is a slight amount of play $(0.5$ to $1.0 \mathrm{~cm})$ between the bolsters. In a study by Chung, ${ }^{39}$ patients were followed prospectively (but nonrandomized) after PEG placement. Physicians positioned the bolsters in either a tight or a loose fashion.
At the end of the study, the distance between bolsters on abdominal radiograph was $4.9 \mathrm{~cm}$ in the "tight" group and $11.6 \mathrm{~cm}$ in the "loose" group. Surprisingly, 13 out of the 14 complications after PEG placement

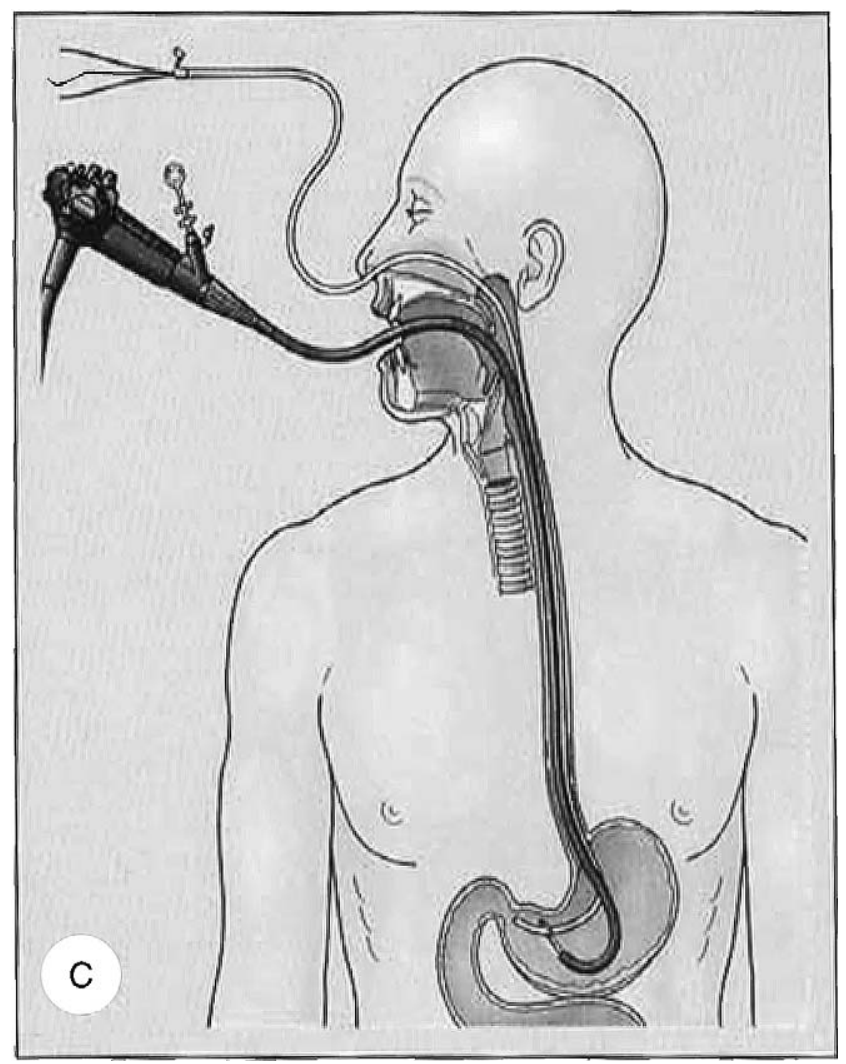

FIGURE 7. Variation of Drag and Pull technique for ENET placement. Reproduced with permission from Clinical Gastrointestinal Endoscopy. Ginsberg GG, et al, eds; 2005:351-356. 


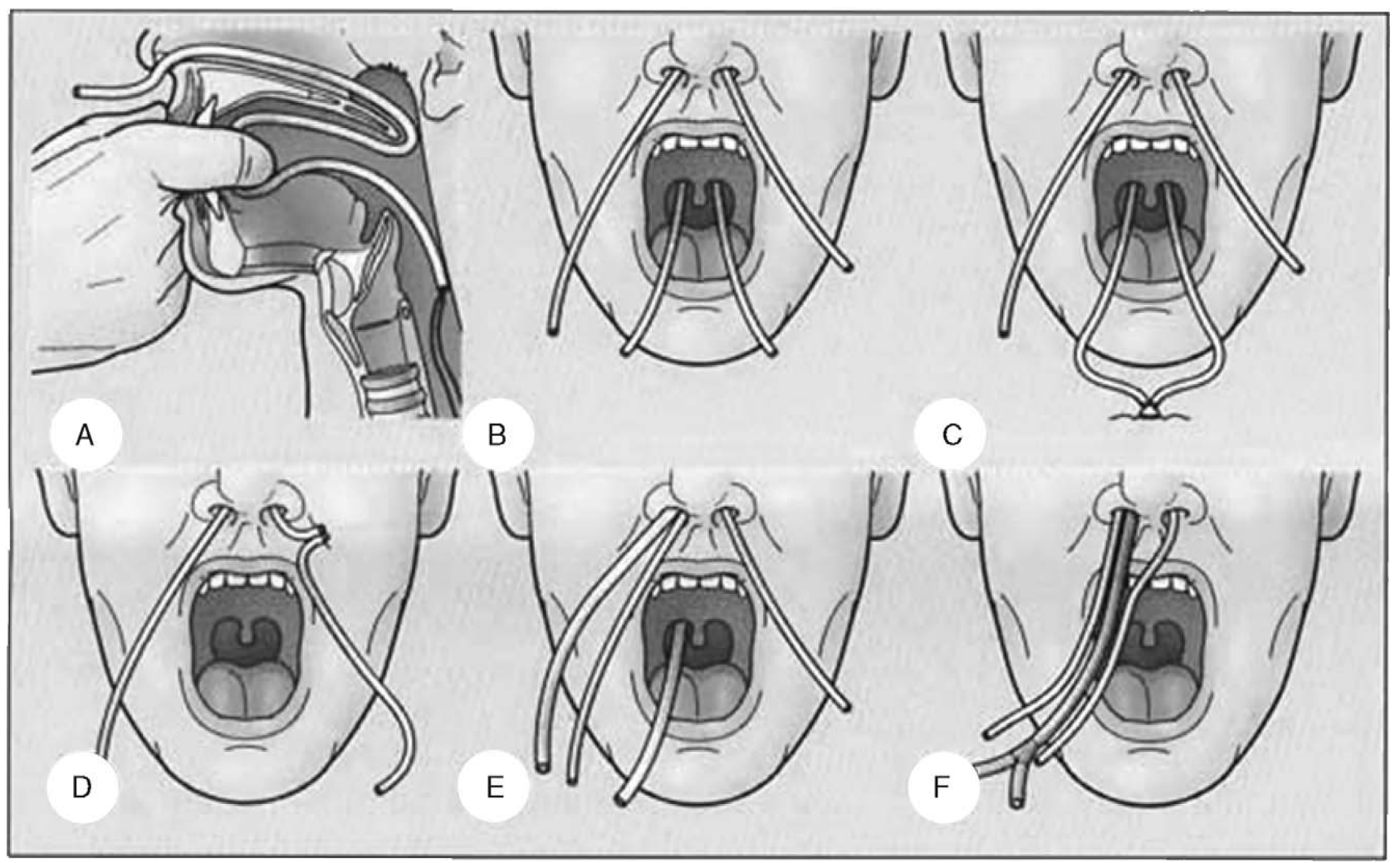

FIGURE 8. Nasal Bridle technique to secure nasoenteric tube. Reproduced with permission from Clinical Gastrointestinal Endoscopy. Ginsberg GG, et al, eds; 2005:351-356.
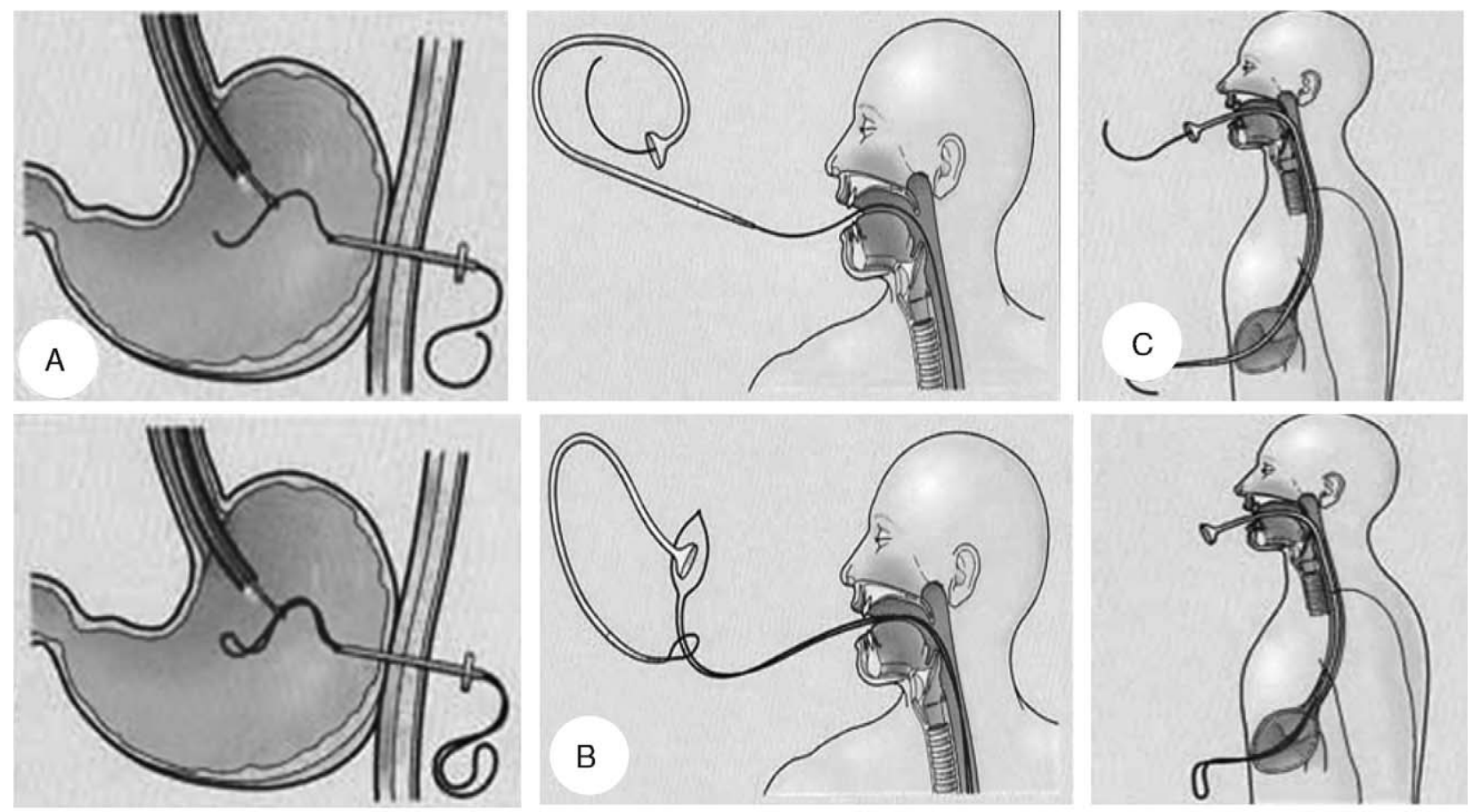

FIGURE 9. Sacks-Vine Push technique (above) and Ponsky Pull technique (below) for PEG placement. Reproduced with permission from Clinical Gastrointestinal Endoscopy. Ginsberg GG, et al, eds; 2005:351-356. 
occurred in the group in which bolsters were cinched tightly. ${ }^{39}$ Thus, leaving some play between the external bolster and the anterior abdominal wall prevents compression and ischemia of the underlying tissue. The external bolster may need to be positioned somewhat more tightly in the first 3 days after initial PEG placement, to allow the tract to mature and seal (thus preventing a leak). After 3 days, the bolster may be repositioned to allow more play.

The technique least familiar to gastrointestinal endoscopists is the "Russell Introducer Technique" for PEG placement ${ }^{40}$ (Fig. 10). This technique is important to use in patients with exophytic oropharyngeal or esophageal carcinoma. In such cases, dragging the tube past the tumor can lead to seeding of the PEG tract and subsequent metastatic cancer implantation. The Russell technique requires placement of $\mathrm{T}$-fasteners and dilation of the PEG tract with a series of Seldinger-type dilators (Fig. 10). The trocar and guidewire are placed initially in a manner identical to that used for the more traditional "Push" and "Pull" techniques. ${ }^{37,38}$ Once the guidewire is in place in the stomach and held with a snare, T-fasteners should be placed. The secret to placing the guidewire is to establish the angle of the tract for each of $4 \mathrm{~T}$-fasteners by using a 23 gauge spinal needle. While the operator attempts to place the T-fasteners in 4 quadrants around the guidewire, invariably the passage of the $\mathrm{T}$-fastener into the stomach do not end up in a 4-quadrant distribution around the wire within the stomach. Placement of each T-fastener is facilitated by making a nick in the skin with a scalpel first. Once $4 \mathrm{~T}$-fasteners are in place, the tract is dilated with 3 or 4 Seldinger dilators, before final passage of the feeding tube into position over the guidewire (Fig. 10).

\section{Placement of a PEGJ}

In cases where patients are intolerant of gastric feeding or where patients are at high risk for aspiration, conversion of a PEG to a PEGJ may be required. The most reliable technique for achieving the deepest jejunal access is the "Johlin Snare Technique",41 (Fig. 11). Once the PEG is in place, it is cut down to a total length of $10 \mathrm{~cm}$. An air valve is fashioned, usually from a plug from another feeding tube (Fig. 12). A standard endoscopic snare is passed through the air valve, which is then passed through the PEG into the stomach. The air valve plug in the end of the PEG tube allows for normal insufflation of the stomach and good endoscopic visualization (Fig. 12). The snare is opened in the stomach, and a pediatric colonoscope passed down through the mouth is driven through the snare and on down into the proximal jejunum as far as possible (Fig. 11). Once in this position, a $480 \mathrm{~cm}$ standard 0.035 gauge guidewire is passed further out into the small bowel, and the endoscope is withdrawn back
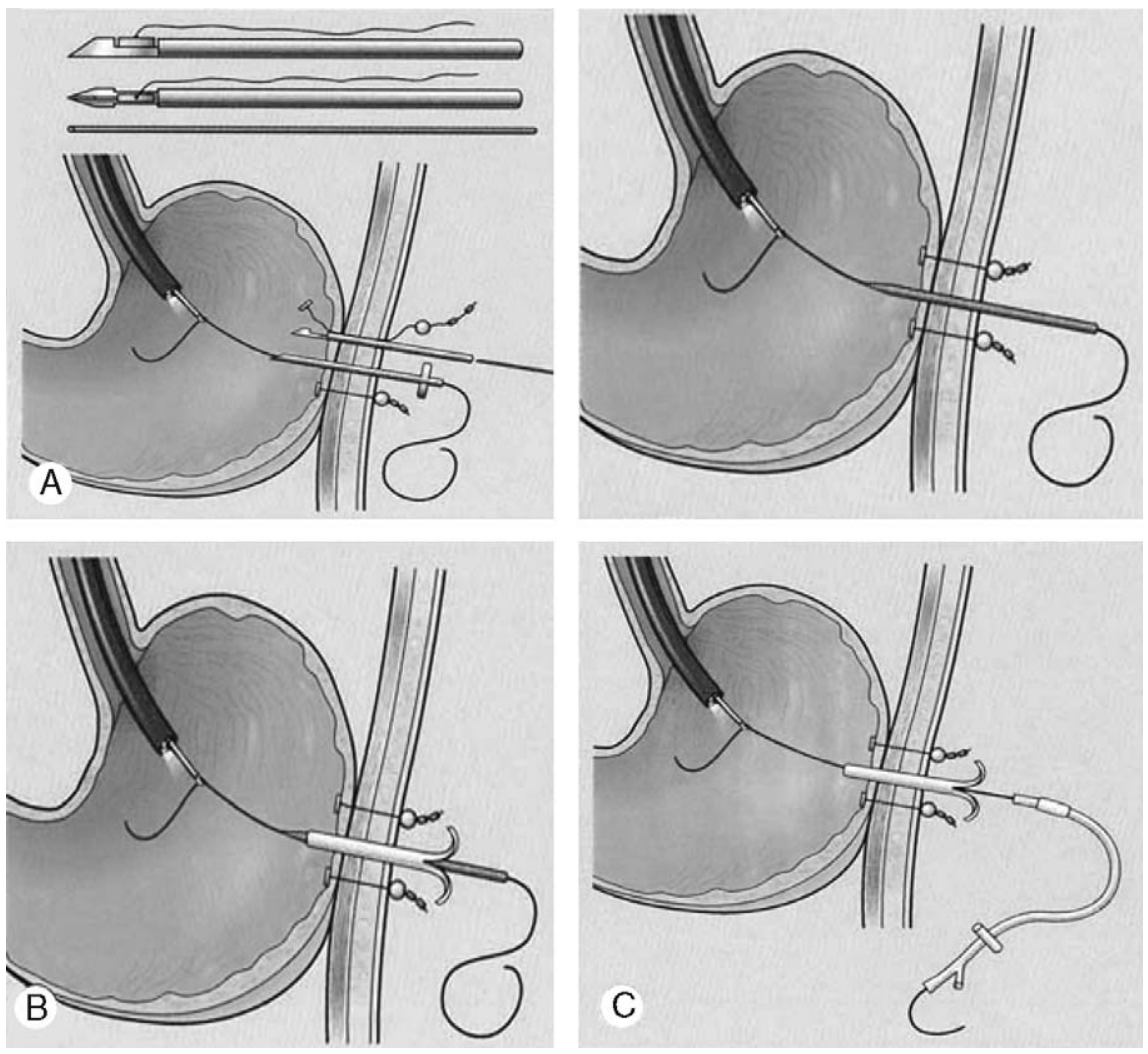

FIGURE 10. Russell Introducer technique for PEG placement. Reproduced with permission from Clinical Gastrointestinal Endoscopy. Ginsberg GG, et al, eds; 2005:351-356. 
into the proximal stomach above the level of the snare. The snare is closed down on the guidewire and subsequently pulled out through the PEG. With the loop of guidewire protruding externally outside the PEG tube, the operator has to determine which side of the wire loop represents the end exiting proximally out the operating channel of the endoscope. This is done by having the assistant pull on the guidewire exiting the endoscope. Once this side of the wire loop is identified, it is pulled out through the PEG. A jejunal tube with Y connector is then passed over the guidewire through the PEG down into position in the small bowel, and the guidewire is withdrawn. Before removing the endoscope, however, it is important to confirm position of the PEGJ tube, with the jejunal tube passing directly from the PEG to the pylorus, without a large loop in the stomach (Fig. 11).

An alternative to the above mentioned snare technique is the "Over the Guidewire Technique"
(Fig. 13). For this procedure, an air valve is again fashioned and positioned in the shortened PEG tube. But this time instead of a snare, a guidewire is passed through the air valve into the stomach, grabbed with biopsy forceps, and dragged down further into the small bowel. While the standard gastroscope that is used usually can be passed no further than the fourth portion of the duodenum, the wire can be passed out further hopefully beyond the Ligament of Treitz. The biopsy forceps is passed as far as possible and then the scope is withdrawn back into the proximal stomach above the level of the PEG, while holding the tip of the wire in place with the forceps. The jejunal tube is passed over the guidewire down into position under direct endoscopic visualization. A biopsy forceps is used instead of a snare in order that the wire can be released effectively once the tube is in the proper position (Fig. 13).
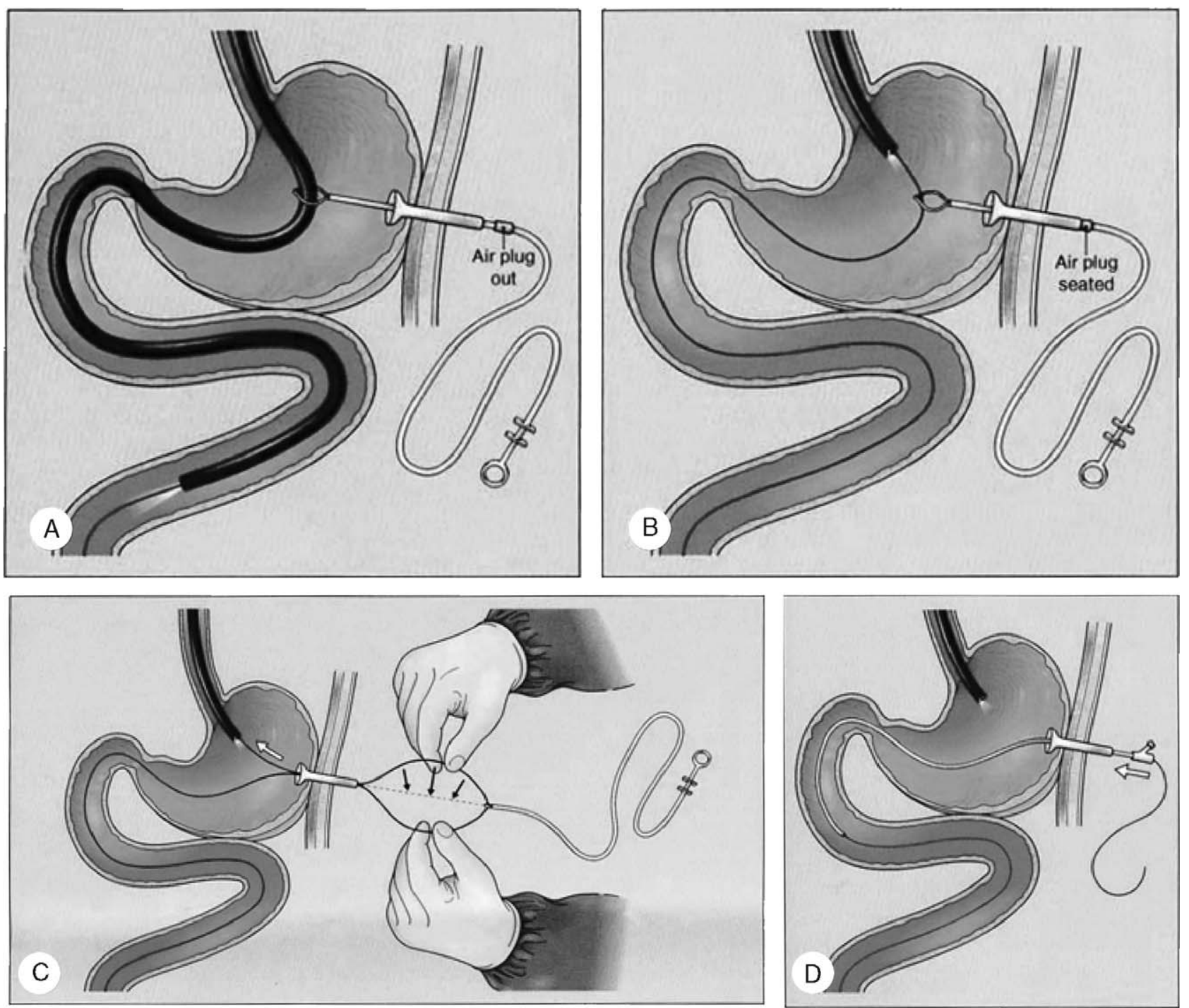

FIGURE 11. The Johlin Snare technique for PEGJ placement. Reproduced with permission from Clinical Gastrointestinal Endoscopy. Ginsberg GG, et al, eds; 2005:351-356. 


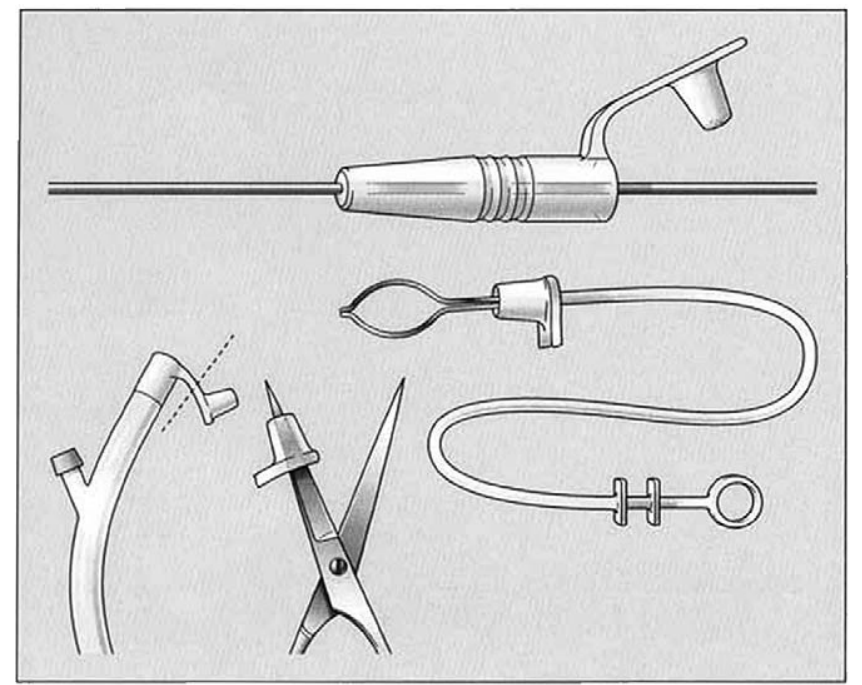

FIGURE 12. Commercial and homemade versions of an air valve to maintain gastric insufflation. Reproduced with permission from Clinical Gastrointestinal Endoscopy. Ginsberg GG, et al, eds; 2005:351-356.

\section{Direct Percutaneous Endoscopic Jejunostomy}

The most challenging and yet most rewarding technique for deep jejunal access is the direct percutaneous endoscopic jejunostomy (DPEJ) technique (Fig. 14). This is clearly a 2-man technique, and requires a partner or senior fellow with good endoscopic skills. In general, the procedure is longer in duration than typical PEG placement, and may require up to 30 to 45 minutes to effectively transluminate and find a proper location for
DPEJ placement. A key to success is establishing a tract into the small bowel using a 23 gauge spinal needle. The procedure may require up to 15 to 20 sticks with the sounding needle to achieve appropriate positioning. A larger area on the patient's abdominal wall should be prepared anesthetically, as position of the final DPEJ may range anywhere vertically from the iliac crest to the costal margin, and horizontally from the linea alba in the midline laterally to the midaxillary line. In patients who have had previous GI surgery, the duodenum often has been brought out into the peritoneal space. For these cases, the entire abdomen has to be prepped, as the final position of the DPEG may even be far on the patient's other side to the right of the midline. Again, a pediatric colonoscope (not a small bowel enteroscope) is used, with the tip passed down just beyond the Ligament of Treitz. It is important to have 5 to $10 \mathrm{~cm}$ of small bowel out ahead at the tip of the endoscope, to allow an operating distance which facilitates the passage of the spinal needle and the final trocar. With the scope positioned just beyond the Ligament of Treitz, the assistant performs finger indentation of the abdominal wall to look for translumination (Fig. 14). If he is unsuccessful, the endoscopist passes the scope down around the next loop, further below in the GI tract, and attempts to transluminate are repeated. Once there is successful translumination, a 23 gauge spinal needle is passed into the loop of small bowel. Expeditiously, the endoscopist grabs the sounding needle with the snare and holds it in position. The assistant then passes the main trocar along side the sounding needle, in a similar angle and pathway, to enter the loop of small bowel. Once the trocar is visualized in the small bowel, the snare is transferred from the spinal needle to the
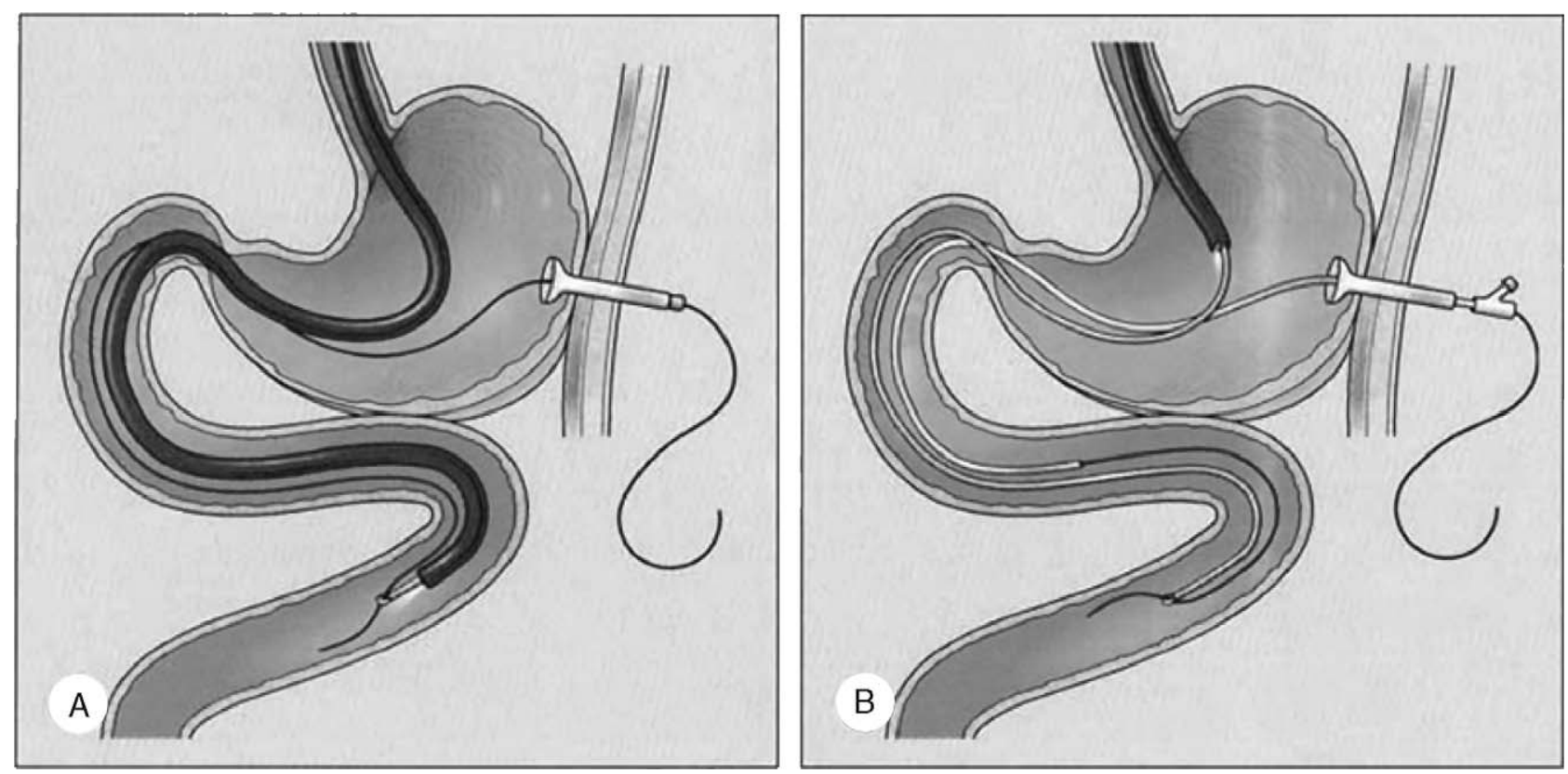

FIGURE 13. Over the guidewire technique for PEGJ placement. Reproduced with permission from Clinical Gastrointestinal Endoscopy. Ginsberg GG, et al, eds; 2005:351-356. 

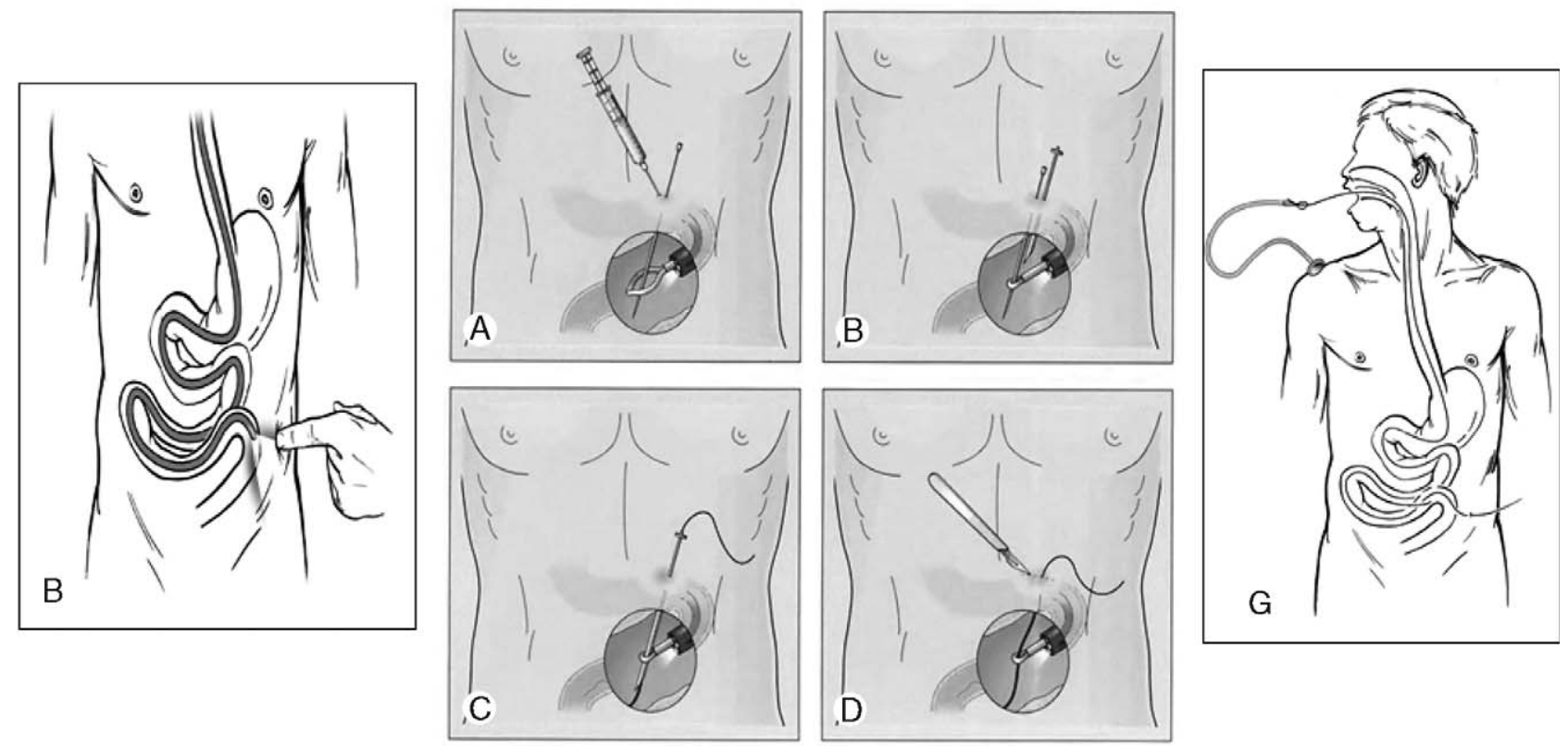

FIGURE 14. Technique for DPEJ. Reproduced with permission from Clinical Gastrointestinal Endoscopy. Ginsberg GG, et al, eds; 2005:351-356 and from Tech Gastroint Endosc 2001;3:46-47.

trocar. A wire loop guidewire is passed through the trocar, grabbed with the snare, and brought back through the proximal GI tract and out the mouth. Only at this point is the skin at the exit side of the guidewire effectively anesthetized and a skin incision is made. A "Pull-type" 20-French PEG (or smaller 15-16-French pediatric PEG) is attached to the wire loop guidewire using the "Ponsky Pull Technique." 37 The "Pull" technique is used in favor of the "Push" technique, because the plastic leader on the "Push" PEG may not be long enough to reach down through the stomach to the exit site in the proximal jejunum. ${ }^{37,38}$ Also of importance in selection of the feeding tube is an internal bolster that is low profile. A large inflatable balloon on a DPEJ tube may lead to intermittent small bowel obstruction. As the DPEJ tube is pulled down through the small bowel, the external bolster tends to "seat" itself at each bend of the small bowel. Thus, it is important to follow the tube down with the endoscope and confirm final position with direct visualization (Fig. 14).

\section{ASSESSMENT AND MONITORING OF THE PATIENT ON EN}

As our priorities for nutritional management have changed over the past decade, so have issues related to nutritional assessment. In the past, nutrition support specialists were preoccupied with preventing protein energy malnutrition (PEM), as older data suggested a prevalence of PEM of over $50 \%$ of hospitalized patients in the United States. "H2 "Hyperalimentation" was a typical strategy of nutrition support with patients receiving $35-45 \mathrm{Kcal} / \mathrm{kg} / \mathrm{d}$. Usual practice was to wait for the presence of bowel sounds before initiating EN. Assess- ment focused on visceral protein levels (albumin, transferrin, and prealbumin), measuring anthropometrics (arm muscle circumference, triceps skin fold thickness, and creatinine height index), and monitoring aspiration with blue food coloring and gastric residual volumes. Changes in nutritional assessment had occurred out of necessity, as we are currently in an era of obesity in the United States. More recent studies would suggest that the true prevalence of PEM in hospitalized patients is closer to $8 \%$ to $12 \%{ }^{43}$ Multidisciplinarian nutrition teams now realize the dangers of overfeeding. As a result, patients are fed more appropriately, in the range of 20 to $25 \mathrm{Kcal} / \mathrm{kg} / \mathrm{d}$. As teams are more aggressive in their efforts to provide EN, clinicians are encouraged to "feed an ileus" by accessing the small bowel, decompressing the stomach, and initiating feeds to stimulate promotility agents. The goal of nutrition support is no longer to prevent PEM, but to modulate oxidative stress and set the tone for systemic immunity. Assessment now is relegated to evaluating gut function, determining disease severity (to see whether the degree of critical illness is great enough to warrant the need for specialized nutrition support), and selecting more appropriate monitors for risk of aspiration and complications of EN.

Providing EN in the critical care setting is much more difficult than provision of PN. In our own institution, we found significant problems in both initiating and delivering EN to the critically ill patient. ${ }^{44}$ With regard to initiation of feeds, physicians ordered only $65 \%$ of goal calories day in and day out. This underordering of calories was due to slow ramp-ups, cutting the strength of the formulas, and delays in getting feeds started. Few patients (only 15\%) reached goal feeds within 3 days. ${ }^{44}$ Once feeds were initiated, however, more 
problems were encountered in the continued delivery. Cessation of EN occurred in $80 \%$ of the patients for approximately $20 \%$ of the infusion time. ${ }^{44}$ As a result, patients only received $80 \%$ of the prescribed formula. When these errors involving initiation and delivery were combined, the end result was that patients only received a net $50 \%$ of goal feeds (goal defined as the volume required to meet caloric requirements). ${ }^{44}$ Achieving the benefits of EN is a dose-dependent effect, and providing $50 \%$ of goal caloric requirements is barely in the range required to maintain gut integrity and achieve the clinical end points desired from EN.

A number of factors have been identified which serve as roadblocks, obstructing the delivery of EN. Surprisingly, over two-thirds of the reasons for cessation related to these factors turn out to be inappropriate. ${ }^{44}$ Perceived patient intolerance accounts for $35 \%$ of cessation time, while making patients nil per os (NPO) after midnight for procedures and diagnostic tests account for $40 \%$ of the cessation time. ${ }^{44}$ Residual volumes result in cessation of EN $15 \%$ of the potential infusion time, and tube displacement (which involves $41 \%$ of patients) accounts for $8 \%$ of the cessation time. Factors related to nursing care account for the remainder ( $<2 \%$ of cessation time). ${ }^{44}$ Scrutinizing these reasons for cessation and altering strategies for management and delivery of EN are important to ensure that a sufficient volume of feeding is delivered.

Assessing and promoting tolerance may be the most important aspect of monitoring of the patient on EN. Segmental contractility of the GI tract is evaluated by examining nasogastric output from the stomach. Once the volume is below $1200 \mathrm{~mL} / \mathrm{d}$, it may be presumed that $75 \%$ of the volume of salivary and gastric secretions (which normally totals $5000 \mathrm{~mL} / \mathrm{d}$ ) is passing out of the stomach. Small bowel contractility may be assessed by abdominal distention, bowel sounds, and air fluid levels on abdominal radiograph. Colonic contractility is evaluated by the passage of flatus and stool. Based on this evaluation of segmental contractility, the proper tube and level of feeds may be selected, and the need for decompression of the stomach may be determined. The clinician should be aggressive in correcting electrolytes, as well as reassessing and if possible, reducing sedation and analgesia. If it is inappropriate to remove sedation and analgesia, their effect on gut contractility may be minimized by infusing 2 amps $(8 \mu \mathrm{g})$ of Naloxone ${ }^{45}$ through the nasoenteric tube every 6 hours to reverse the effects of the opioid narcotics at the level of the gut. Efforts to minimize the period of ileus after an injury or surgical procedure help promote tolerance. Clinicians should be encouraged to feed an ileus in the absence of shock or hemodynamic instability. The value of infusion of Narcan to promote tolerance was shown in a recent study of critically ill patients on mechanical ventilation and fentanyl anesthesia. ${ }^{45}$ Eightyfour patients were randomized to receive either $8 \mathrm{mcg}$ of Narcan or placebo every 6 hours through the nasogastric tube. In comparison to those patients who received placebo, those who were given Narcan received a nonsignificantly greater amount of EN, demonstrated significantly lower gastric residual volumes, and showed a significantly reduced incidence of pneumonia (56\% vs. $34 \%, P=0.04){ }^{45}$

Continuing feeds closer to the time of a diagnostic test or procedure helps reduce down time from the provision of EN. In a study at our institution, patients undergoing routine upper endoscopy were randomized to either NPO after midnight, clear liquids up to 2 hours before the procedure, formula $(240 \mathrm{~mL})$ up to 4 hours prior, or formula up to 2 hours before the procedure. ${ }^{46}$ Those patients receiving formula up to 2 hours before the procedure did have a significantly greater volume of gastric contents than the other 3 groups, but the mean volume was only $70 \mathrm{~mL}$ (approximately 4 to 5 tablespoons). Those patients who received formula up to 4 hours before the endoscopic procedure showed no evidence of formula remaining in the stomach and had a volume that was no different than the group of patients on clear liquids or those patients who were NPO after midnight. ${ }^{46}$ In a burn study involving daily burn wound debridement under general anesthesia, patients were randomized to either continuing or discontinuing feeding throughout the surgical procedure. ${ }^{47}$ Results showed that wound infections were reduced 4 -fold from $22 \%$ down to $5 \%(P<0.05)$, comparing those patients who received feeds to those in which feedings were held. Surprisingly, there were no problems with aspiration, vomiting, or pneumonia in the group that was fed through general anesthesia. ${ }^{47}$

The most feared complication arising from the provision of $\mathrm{EN}$ is aspiration. The ability of the clinician to monitor such an event is limited. Two recent studies of similar design evaluated the incidence of regurgitation and aspiration in patients on mechanical ventilation in the ICU. ${ }^{48,49}$ One study used yellow colorimetric microspheres mixed with the EN formula, ${ }^{49}$ whereas the other study used pepsin as a marker of gastric secretions. ${ }^{48}$ Patients were monitored at the bedside every 4 hours while on mechanical ventilation, with aspiration confirmed by the presence of yellow color (detected by colorimetric fluorometer) or pepsin in the tracheal secretions. Evidence of aspiration was detected on $22.1 \%$ to $31.3 \%$ of the bedside evaluations. ${ }^{48,49}$ Such aspiration events occurred in the majority of patients, ranging from $75 \%$ to $89 \%$ between the 2 studies. ${ }^{48,49}$ These aspiration events were frequent, unwitnessed, and unmeasurable. The methods of detection used in these 2 studies were research techniques and could not be used in a clinical setting for monitoring purposes. Progression from simple aspiration to aspiration pneumonia is difficult to predict, and a variety of host factors (age, immune status, existence of comorbidities) and factors related to the aspirate itself (volume, acidity, particulate vs. nonparticulate, and contamination) all affect whether or not pneumonia results. Although aspiration is probably the mechanism of pneumonia in the majority of cases in the ICU, aspiration of colonized oropharyngeal secretions is probably much more clinically significant 
than aspiration of contaminated gastric secretions. ${ }^{50-52}$ Thus, although a number of strategies may be involved to reduce risk of aspiration of enteral formula, whether or not a patient actually gets aspiration pneumonia in the ICU may be more related to his own dental health and oropharyngeal mouth care provided by the nursing service. In the study using pepsin as a marker for aspiration of gastric secretions, patients were noted to have an increasing number of cumulative aspiration events as their days in the ICU progressed. ${ }^{48}$ With increasing number of aspiration events, the risk for pneumonia increased significantly. At the conclusion of the study, the number of aspiration events were evaluated with respect to patient outcome. Those patients found to have a high number of aspiration events had a significantly longer hospital length of stay, ICU length of stay, and duration of mechanical ventilation than those patients with a low number of aspiration events. $^{48}$

Current monitors for aspiration are incapable of identifying or quantifying these unwitnessed aspiration events. Glucose oxidase strips and blue food coloring added to the enteral feeding are no longer useful as monitors for aspiration. Although use of gastric residual volumes as a monitor for risk of aspiration is still practiced in virtually every ICU across the country, interpretation of these values needs to be revised. With a known volume of salivary and gastric secretions of nearly $5000 \mathrm{~mL} / \mathrm{d}$, and a rate of infusion of $\mathrm{EN}$ of 25 to $125 \mathrm{~mL} / \mathrm{h}$, a clinician may expect a volume up to $464 \mathrm{~mL}$ passing through the stomach every hour under normal conditions. ${ }^{53}$ If gastric residual volumes are used to detect gastric dysfunction and identify those patients in whom formula is being retained, choosing any volume less than this value does not make physiologic sense. ${ }^{53}$

If there is a close relationship between aspiration and gastric residual volumes, then changing the cut-off value for residual volume should affect risk of aspiration. In other words, in a patient who is doing well and seems to be tolerating EN, conceivably the cut-off value for residual volume could be increased with some degree of risk for increasing aspiration. In contrast, if there was concern for aspiration in a particular patient, the number could be decreased in the hopes of protecting the patient against aspiration. Two prospective randomized trials using different cut-off values for gastric residual volumes would suggest that this does not occur. ${ }^{49,54}$ In our study from Louisville, using colorimetric microspheres, patients were randomized to have either a $400 \mathrm{~mL}$ or a $200 \mathrm{ml}$ cutoff value for gastric residual volume. ${ }^{49}$ Incidence of aspiration between the 2 groups was no different $(22.6 \%$ vs. $21.6 \%, P=\mathrm{NS}){ }^{49}$ In a Canadian study, Pinella randomized patients to $150 \mathrm{~mL}$ versus $250 \mathrm{~mL}$ cut-off, and again intolerance (most of which was related to aspiration) was no different between the 2 groups. ${ }^{54} \mathrm{In}$ fact, in the Louisville study, in which aspiration events were well identified, gastric residual volumes were compared over a range of residual volumes from 0 to $500 \mathrm{~mL}$. There was no significant difference in the
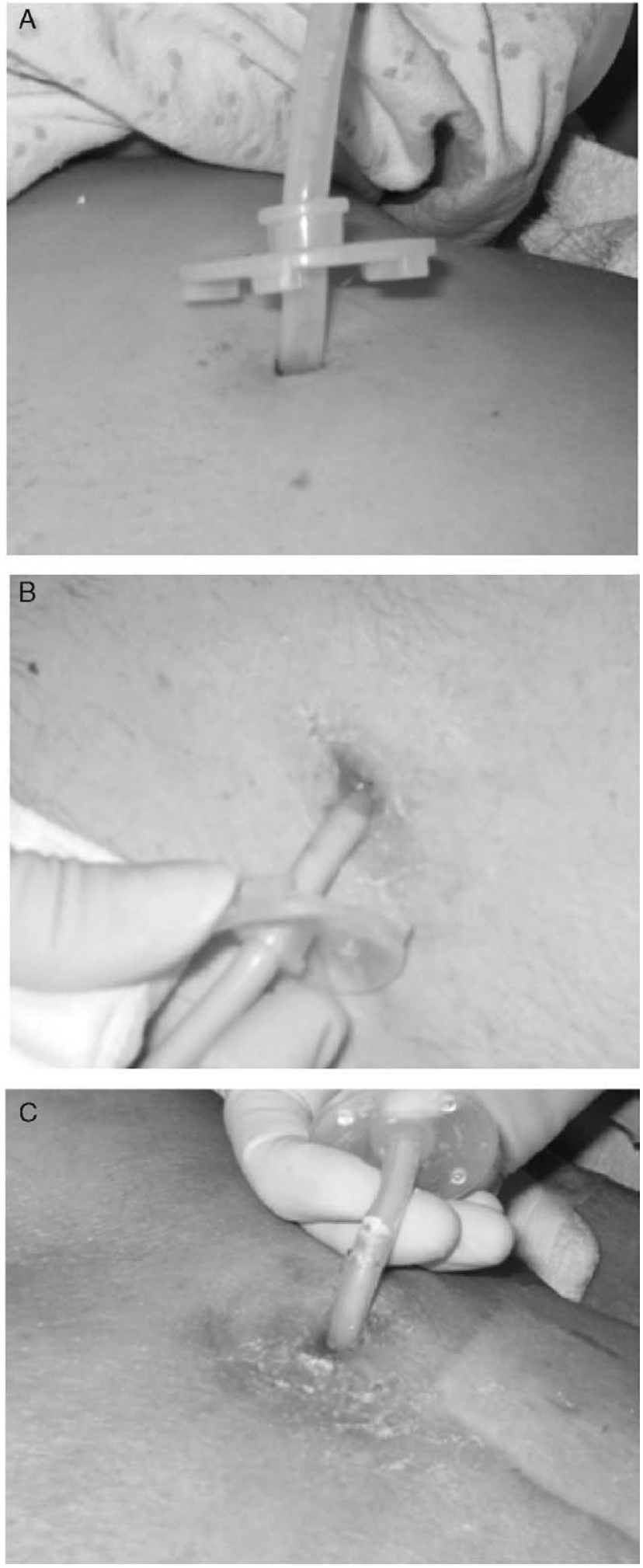

FIGURE 15. Physical examination of a healthy PEG site. Reproduced with permission from JPEN 2006;30:S30-S36.

incidence of aspiration when residual volumes were in the range of 0 to $100 \mathrm{~mL}$, than when they were in a range of 300 to $500 \mathrm{~mL}$. 

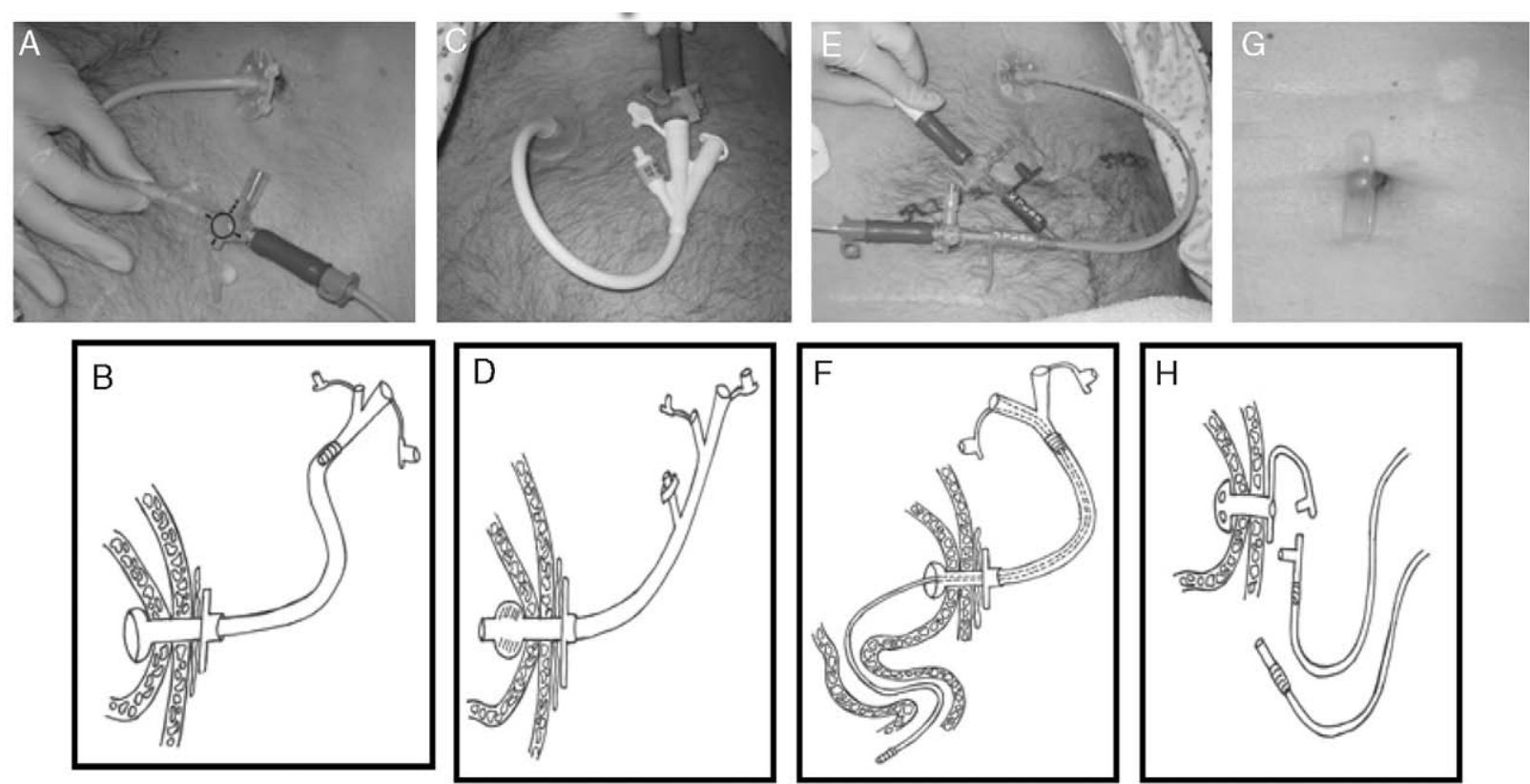

FIGURE 16. Skin-level view of PEG tubes and the type of tube that has been placed. Reproduced with permission from JPEN 2006;30:S30-S36.
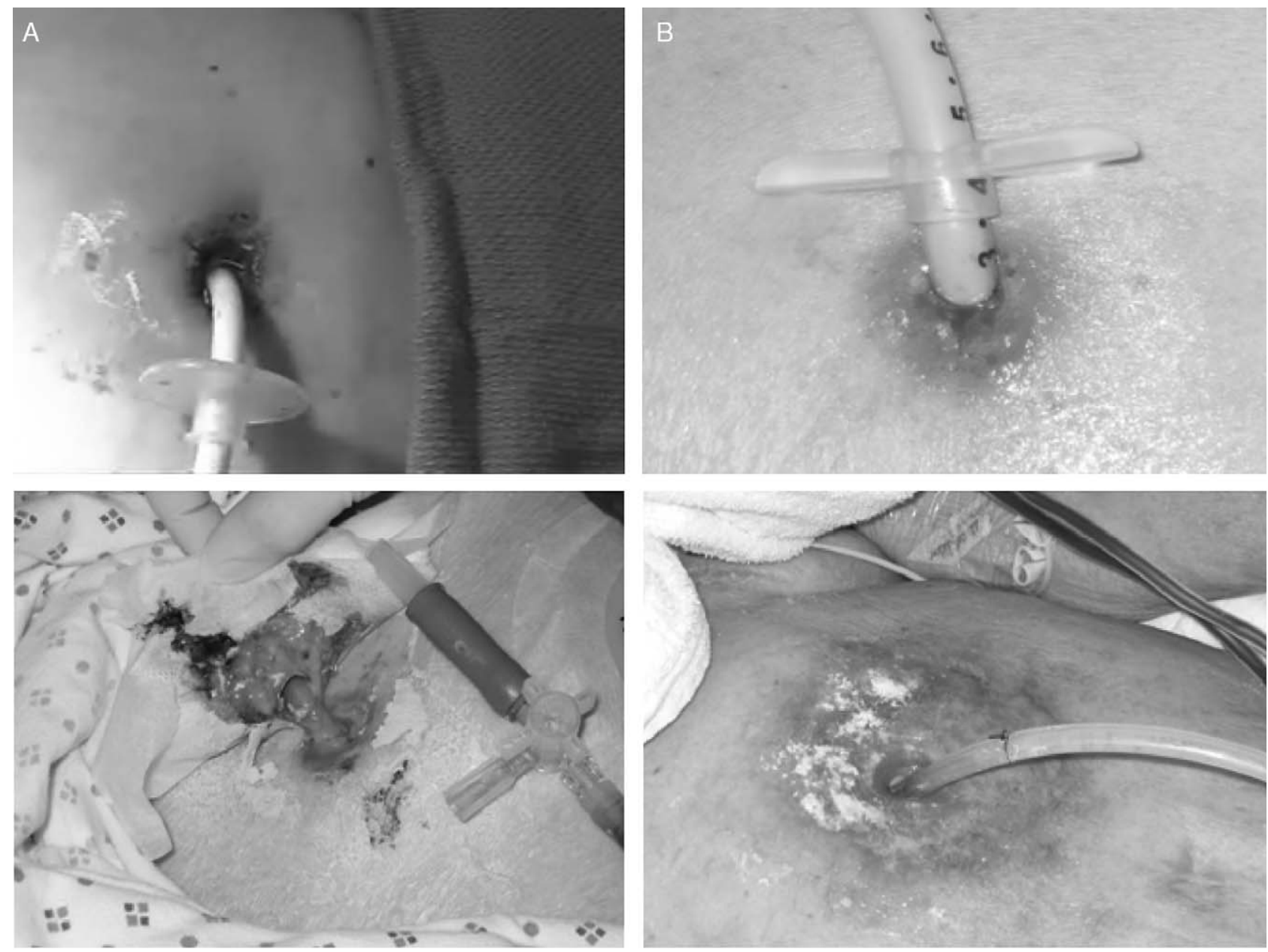

FIGURE 17. Breakdown of the PEG site. Reproduced with permission from JPEN 2006;30:S30-S36. 
Because monitors for risk of aspiration are so faulty, clinicians may better spend their time focusing on strategies to modify or reduce risk of aspiration. Chlorhexedine mouthwash has been shown to reduce nosocomial aspiration pneumonia by as much as $70 \%$ in patients undergoing cardiac surgery. ${ }^{55}$ Use of a specialized endotracheal tube, which provides continuous aspiration of subglottic secretions, was shown to reduce ventilator-associated pneumonia by as much as $50 \%{ }^{56}$ Diverting the level of EN infusion lower in the GI tract reduces gastroesophageal reflux and risk for aspiration, and may reduce the incidence of pneumonia. Using a radioisotope placed in the EN formula, Heyland ${ }^{57}$ showed that reducing the level of infusion from the stomach down to the third portion of the duodenum significantly reduced reflux and aspiration. Whether or not this reduction in reflux and aspiration reduces pneumonia is not as clear. In a meta-analysis of 9 studies, use of postpyloric feeds was shown to reduce pneumonia by $24 \%$, compared to gastric feeds $(P<0.05){ }^{8,58}$ In a second meta-analysis comparing only 7 of those 9 studies, a similar trend was seen, but it did not reach statistical significance. $^{59}$

The gastrointestinal endoscopist is often called for service because of tube occlusion, a complication which occurs in $9 \%$ to $20 \%$ of patients on EN. ${ }^{60}$ Studies by Marcuard ${ }^{60}$ have shown that the best declogging agent is a Viokase pancreatic enzyme preparation combined with bicarbonate and mixed in warm water. This combination of agents is twice as effective as soft drinks, which in turn is twice as effective as papain meat tenderizer or Viokase in the absence of the bicarbonate tablet. If use of the declogging agent in a syringe on the end of the feeding tube is unsuccessful in alleviating the clog, an endoscopic retrograde cholangiopancreatography catheter may be placed down through the feeding tube and the declogging agent instilled down at the level of the clog. ${ }^{60}$ If these efforts are unsuccessful, use of a cytology brush or a long

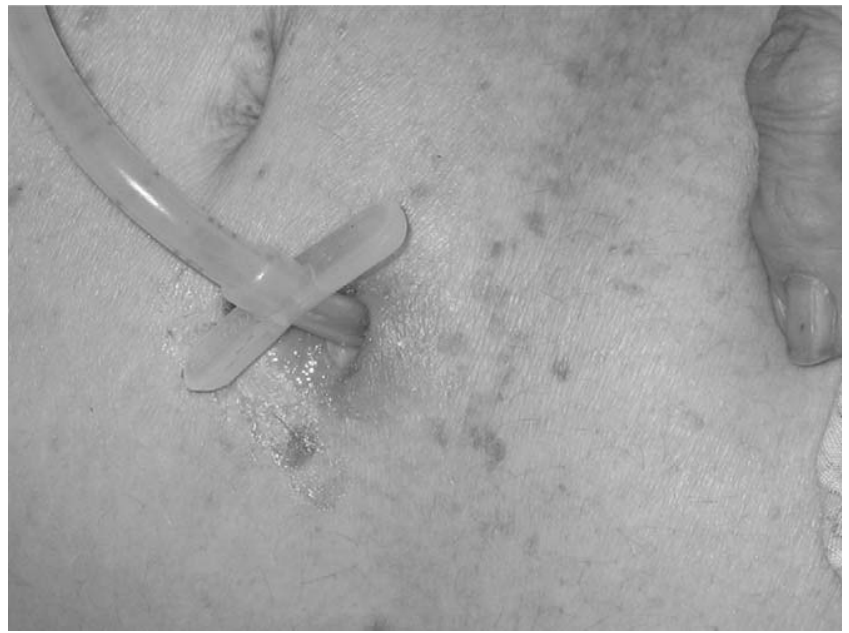

FIGURE 18. Infection at the PEG site. Reproduced with permission from JPEN 2006;30:S30-S36. plastic commercial corkscrew device may be passed down through the feeding tube to gently mechanically declog the tube.

An odd complaint of stool around the PEG tube, or diarrhea that is so bad that the effluent from the rectum looks identical to the formula infused in the PEG tube, may indicate the development of a gastrocolocutaneous fistula. The diagnosis is confirmed by infusion of contrast through the PEG tube with an abdominal radiograph showing the appearance of what looks like a barium enema. Management of this complication is surprisingly simple. The PEG tube may be pulled, a bandage may be placed over the site, and a nasojejunal tube placed to
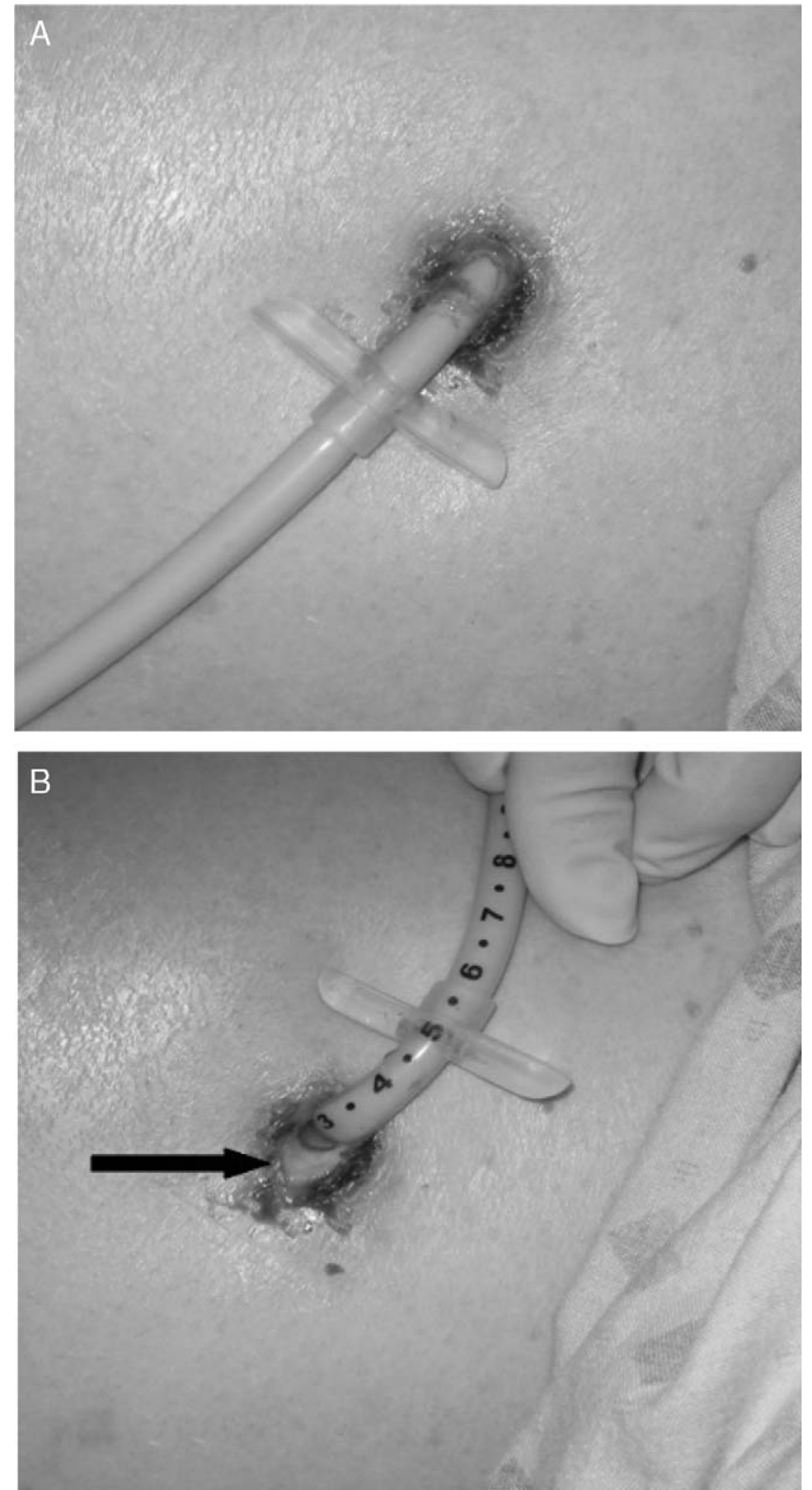

FIGURE 19. Side torsion with resulting ulceration of the tract. Reproduced with permission from JPEN 2006;30:S30-S36. 


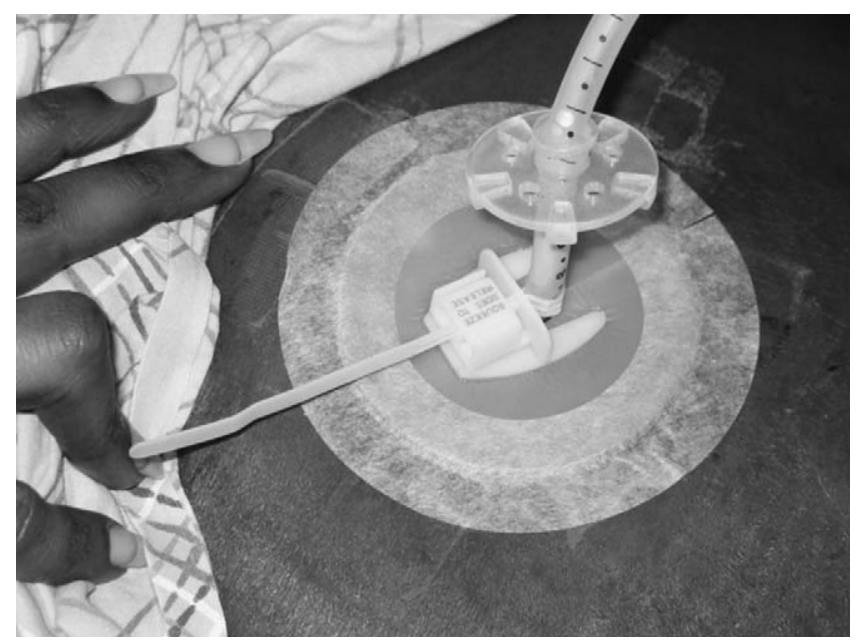

FIGURE 20. Commercial vertical clamping device to stabilize shaft of PEG tube. Reproduced with permission from JPEN 2006;30:S30-S36.

facilitate continuation of enteral feeds. Seven to ten days later, a new PEG may be placed at a different site within the stomach.

Buried bumper syndrome is a common complication occurring usually as a result of compression between the internal and external bolster. The complication is confirmed by inability to pass the feeding tube in and out. Again, the management of this complication is surprisingly simple. The endoscopist must first determine which direction of removal, pulling the tube out through the skin or pulling it back into the stomach and out through the mouth, would cause less trauma to the PEG site. Once the old tube is removed, a new PEG tube can be placed at the same site with bolsters positioned under direct endoscopic visualization.

The most common request for gastrointestinal endoscopists is to evaluate the patient with breakdown of the PEG site. A healthy PEG site should be clean and dry with no exudate and no evidence of drainage around the PEG tube. The tissue has a natural tendency to close down on the tube (Fig. 15). The clinician should be able to evaluate the PEG from the outside and tell what type of tube has been placed (Fig. 16). The complaint of breakdown of the PEG site varies from excess leakage or an enlarging hole around the PEG, to breakdown of the tissue at the PEG site (Fig. 17). Once leakage around the PEG tube develops, it is important to stop any corrosive factors. Vitamin $\mathrm{C}$ or ascorbic acid is often given by wound care nurses to promote wound care, hydrogen peroxide washes are often used to keep the PEG site clean, and pharmacies often have "stop orders" leading to cessation of proton pump inhibitor therapy. Thus, converting to soap and water for PEG site cleansing, stopping the vitamin $\mathrm{C}$, and initiating proton pump inhibitor therapy will help reduce the corrosive effects of the gastric contents exuding out around the PEG.

A number of factors may contribute to breakdown of the PEG site. Early warmth, erythema, tenderness, and light exudate may indicate PEG site infection (Fig. 18). The most common is side torsion on the wall of the tract creating an ulcer (Fig. 19). Stabilizing side-to-side torsion with a vertical clamping device may be required to allow healing of the tract (Fig. 20). Another frequent factor in breakdown of the site is the absence of an external bolster, which may occur because of breakdown of sutures of a surgically placed feeding tube, or because of replacement of the feeding tube with a Foley catheter (Fig. 21). In these cases, passage of the tube back and forth in the PEG tract will cause a breakdown of the site. This complication can be managed easily by fashioning an external bolster for the Foley catheter or the surgical tube, or replacing with a commercial PEG replacement kit that has an external bolster. Fungal infection of the PEG site is demonstrated by a red erythematous lumpy, bumpy rash (Fig. 22). Frequently, the same rash may be found elsewhere on the patient
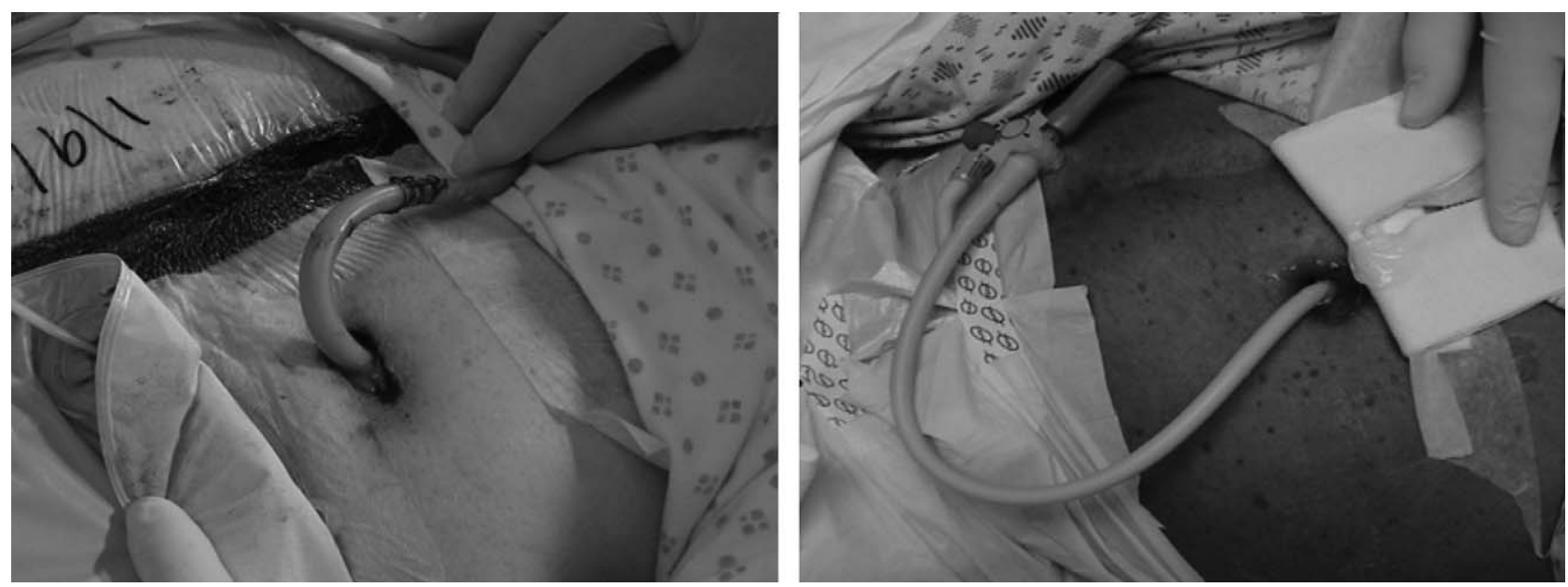

FIGURE 21. Breakdown of the tract because of the absence of external bolster. Reproduced with permission from Gastrointest Endosc 2003;58:744-745. 

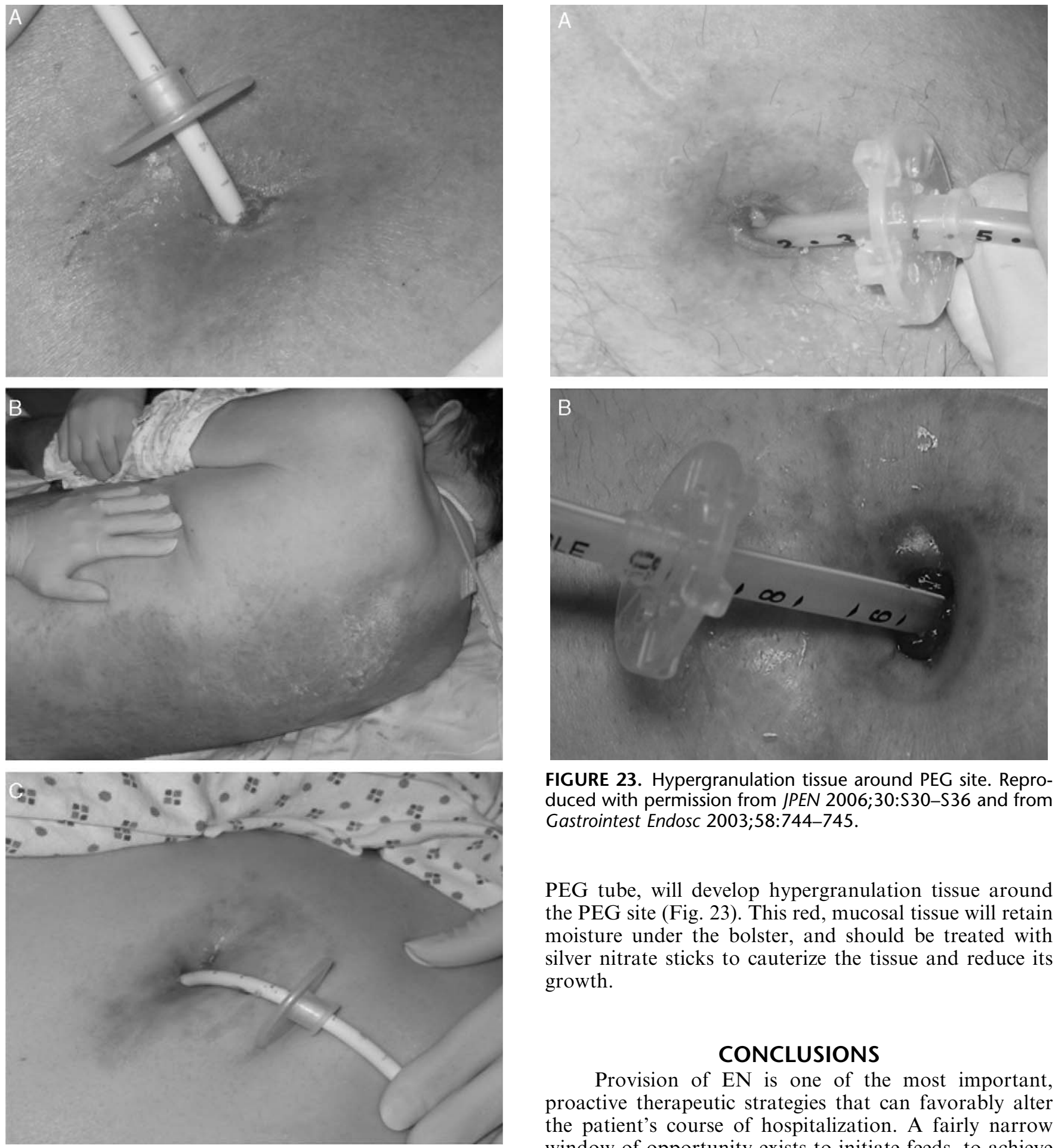

FIGURE 23. Hypergranulation tissue around PEG site. Reproduced with permission from JPEN 2006;30:S30-S36 and from Gastrointest Endosc 2003;58:744-745.

PEG tube, will develop hypergranulation tissue around the PEG site (Fig. 23). This red, mucosal tissue will retain moisture under the bolster, and should be treated with silver nitrate sticks to cauterize the tissue and reduce its growth.

\section{CONCLUSIONS}

Provision of EN is one of the most important, proactive therapeutic strategies that can favorably alter the patient's course of hospitalization. A fairly narrow window of opportunity exists to initiate feeds, to achieve attenuation of oxidative stress, and to modulate systemic immunity. The services of a gastrointestinal endoscopist are myriad to the multidisciplinary nutrition team. The ability to achieve deep jejunal access, the expertise to evaluate gut function and monitor tolerance, and the skills to manage complications are key issues which facilitate the delivery of EN and promote a favorable outcome.

of a patient's trunk. Use of antifungal agents will help clear the rash and reduce the amount of moisture retained at the site. Some patients, with an otherwise normal

FIGURE 22. Fungal infection or colonization of the PEG site Reproduced with permission from JPEN 2006;30:S30-S36. 


\section{REFERENCES}

1. Braunschweig CL, Levy P, Sheean PM, et al. Enteral compared with parenteral nutrition: a meta-analysis. Am J Clin Nutr. 2001; 74:534-542.

2. Lewis SJ, Egger M, Sylvester PA, et al. Early enteral feeding versus "nil by mouth" after gastrointestinal surgery: systematic review and meta-analysis of controlled trials. BMJ. 2001;323:773-776.

3. Jabbar A, Chang WK, Dryden GW, et al. Gut immunology and the differential response to feeding and starvation. Nutrit Clin Pract. 2003; 18:461-482.

4. Fink MP. Why the GI tract is pivotal in trauma, sepsis, and MOF. J Crit Illness. 1991;6:253-269.

5. Doig CJ, Sutherland LR, Sandham JD, et al. Increased intestinal permeability is associated with the development of multiple organ dysfunction syndrome in critically ill ICU patients. Am J Respir Crit Care Med. 1998;158:444-451.

6. Deitch EA. Role of the gut lymphatic system in multiple organ failure. Curr Opin Crit Care. 2001;7:92-98.

7. Peng YZ, Yuan ZQ, Xiao GX. Effects of early enteral feeding on the prevention of enterogenic infection in severely burned patients. Burns. 2001;27:145-149.

8. Heyland DK, Dhaliwal R, Drover JW, et al. Canadian Critical Care Clinical Practice Guidelines Committee. Canadian clinical practice guidelines for nutrition support in mechanically ventilated, critically ill adult patients. J Parenter Enteral Nutr. 2003;27: 355-373.

9. Ziegler TR, Smith RJ, O'Dwyer ST, et al. Increased intestinal permeability associated with infection in burn patients. Arch Surg. 1988;123:1313-1319.

10. Kudsk KA. Current aspects of mucosal immunology and its influence by nutrition. Am J Surg. 2002;183:390-398.

11. Marik PE, Zaloga GP. Early enteral nutrition in acutely ill patients: a systematic review. Crit Care Med. 2001;29:2264-2270.

12. Kudsk KA. Importance of enteral feeding in maintaining gut integrity. Tech Gastro Endoscopy. 2001;3:2-8.

13. Dobbins WO. Gut immunophysiology: a gastroenterologist's view with emphasis on pathophysiology. Am J Physiol. 1982;242:G1-G8.

14. Alverdy JC, Laughlin RS, Wu L. Influence of the critically ill state on host-pathogen interactions within the intestine: gut-derived sepsis redefined. Crit Care Med. 2003;31:598-607.

15. Moore EE, Moore FA, Franciose RJ, et al. The postischemic gut serves as a priming bed for circulating neutrophils that provoke multiple organ failure. J Trauma. 1994;37:881-887.

16. Phillips-Qualigiata JM, Lamm ME. Migration of lymphocytes in mucosal immune system. In: Husband AJ, ed. Migration and Homing of Lymphoid Cells. Vol II. Boca Raton, FL: CRC Press; 1988:53-75.

17. King BK, Li J, Kudsk KA. A temporal study of TPN-induced changes in gut-associated lymphoid tissue and mucosal immunity. Arch Surg. 1997;132:1303-1309.

18. Brandtzaeg PE. Current understanding of gastrointestinal immunoregulation and its relation to food allergy. Ann $N$ Acad Sci. 2002;964:13-45.

19. Renegar KB, Small PA Jr. Immunoglobulin A mediation of murine nasal anti-influenza virus immunity. J Virol. 1991;65:2146-2148.

20. Heyland DK, MacDonald S, Keefe L, et al. Total parenteral nutrition in the critically ill patient: a meta-analysis. JAMA. 1998;280:2013-2019.

21. Ammori BJ, Leeder PC, King RF, et al. Early increase in intestinal permeability in patients with severe acute pancreatitis: correlation with endotoxemia, organ failure, and mortality. J Gastrointest Surg. 1999;3:252-262.

22. Moore FA, Moore EE, Poggetti R, et al. Gut bacterial translocation via the portal vein: a clinical perspective with major torso trauma. J Trauma. 1991;31:629-36; discussion 636-638.

23. Oberholzer A, Oberholzer C, Moldawer LL. Sepsis syndromes: understanding the role of innate and acquired immunity. Shock. 2001;16:83-96.

24. Wu Y, Kudsk KA, DeWitt RC, et al. Route and type of nutrition influence IgA-mediating intestinal cytokines. Ann Surg. 1999;229: 662-667.
25. Spiekermann GM, Walker WA. Oral tolerance and its role in clinical disease. J Pediatr Gastroent Nutr. 2001;32:237-255.

26. Fukatsu K, Lundberg AH, Hanna MK, et al. Route of nutrition influences intercellular adhesion molecule-1 expression and neutrophil accumulation in intestine. Arch Surg. 1999;134: 1055-1060.

27. Lebman DA, Coffman RL. Cytokines in the mucosal immune systwem. In: Ogra PL, Lamm ME, McGhee JR, eds. Handbook of Mucosal Immunology. San Diego, CA: Academic Press; 1994: 243-249.

28. Fujiruram Y, Owen R. The intestinal epithelial M-cells: Properties and function. In: Kirschner JB, ed. Inflammatory Bowel Disease. 5th ed. Philadelphia, PA: W.B. Saunders Company; 2000:33.

29. Fukatsu K, Lundberg AH, Hanna MK, et al. Increased expression of intestinal P-selectin and pulmonary E-selectin during intravenous total parenteral nutrition. Arch Surg. 2000;135:1177-1182.

30. Fong YM, Marano MA, Barber A, et al. Total parenteral nutrition and bowel rest modify the metabolic response to endotoxin in humans. Ann Surg. 1989;210:449-456.

31. Evoy D, Lieberman MD, Fahey TH, et al. Immunonutrition: the role of arginine. Nutrition. 1998;14:611-617.

32. Grimm H, Mayer K, Mayser P, et al. Regulatory potential of $\beta 3$ fatty acids in immunological and inflammatory processes. Br J Nutr. 2002;87:S59-S67.

33. Mancuso P, Whelan J, DeMichele SJ, et al. Dietary fish oil and fish and borage oil suppress intrapulmonary proinflammatory eicosanoid biosynthesis and attenuate pulmonary neutrophil accumulation in endotoxic rats. Crit Care Med. 1997;25:1198-1206.

34. Montejo JC, Zarazaga A, Lopez-Martinez J, et al. Spanish Society of Intensive Care Medicine and Coronary Units: immunonutrition in the intensive care unit. A systematic review and consensus statement. Clin Nutr. 2003;22:221-233.

35. Jabbar A, McClave SA. Prepyloric versus postpyloric feeding Clin Nutr. 2005;24:719-726.

36. Smith I, Fleming S, Cernaianu A. Mishaps during transport from the intensive care unit. Crit Care Med. 1990;18:278-281.

37. Gauderer MW, Ponsky JL, Izant RJ, Jr. Gastrostomy without laparotomy: a percutaneous endoscopic technique. J Pediatr Surg 1980;15:872-875

38. Foutch PG, Woods CA, Talbert GA, et al. A critical analysis of the Sacks-Vine gastrostomy tube: a review of 120 consecutive procedures. Am J Gastroenterol. 1988;83:812-815.

39. Chung RS, Schertzer M. Pathogenesis of complications of percutaneous endoscopic gastrostomy-a lesson in surgical principles. Am Surg. 1990;56:134-137.

40. Russell TR, Brotman M, Norris F. Percutaneous gastrostomy. A new simplified and cost-effective technique. Am J Surg. 1984; 148:132-137.

41. Leichus LS, Patel R, Johlin FC. Percutaneous endoscopic gastrostomy/jejunostomy tube placement. Gastrointest Endosc. 1996; $43: 353$

42. Bistrian BR, Blackburn GL, Vitale J, et al. Prevalence of malnutrition in general medical patients. JAMA. 1976;235:1567-1570.

43. The Veteran's Affairs Total Parenteral Nutrition Cooperative Study Group. Perioperative total parenteral nutrition in surgical patients. $N$ Engl J Med. 1991;325:525-532.

44. McClave SA, Sexton LK, Spain DA, et al. Enteral tube feeding in the intensive care unit: factors impeding adequate delivery. Crit Care Med. 1999;27:1252-1256.

45. Meissner W, Dohrn B, Reinhart K. Enteral naloxone reduces gastric tube reflux and frequency of pneumonia in critical care patients during opioid analgesia. Crit Care Med. 2003;31 776-780.

46. McClave SA, Adams JL, Lowen CC, et al. When should enteral nutrition support be stopped prior to a procedure or diagnostic test? J Parenter Enteral Nutr. 2001;25:S14.

47. Jenkins ME, Gottschlich MM, Warden GD. Enteral feeding during operative procedures in thermal injuries. J Burn Care Rehabil. 1994; 15:199-205.

48. Metheny NA, Clouse RE, Chang YH, et al. Tracheobronchial aspiration of gastric contents in critically ill tube-fed patients: 
frequency, outcomes, and risk factors. Crit Care Med. 2006; 34:1007-1015.

49. McClave SA, Lukan JK, Stefater JA, et al. Poor validity of residual volumes as a marker for risk of aspiration in critically ill patients. Crit Care Med. 2005;33:324-330.

50. Torres A, el-Ebiary M, Gonzalez J, et al. Gastric and pharyngeal flora in nosocomial pneumonia acquired during mechanical ventilation. Am Rev Respir Dis. 1993;148:352-357.

51. Bonten MJ, Gaillard CA, van Tiel FH, et al. The stomach is not a source for colonization of the upper respiratory tract and pneumonia in ICU patients. Chest. 1994;105:878-884.

52. Pingleton SK, Hinthorn DR, Liu C. Enteral nutrition in patients receiving mechanical ventilation. Multiple sources of tracheal colonization include the stomach. Am J Med. 1986;80:827-832.

53. Lin HC, Van Citters GW. Stopping enteral feeding for arbitrary gastric residual volume may not be physiologically sound: results of a computer simulation model. J Parenter Enteral Nutr. 1997;21:286-289.

54. Pinilla JC, Samphire J, Arnold C, et al. Comparison of gastrointestinal tolerance to two enteral feeding protocols in critically ill patients: a prospective, randomized controlled trial. J Parenter Enteral Nutr. 2001;25:81-86.
55. DeRiso AJ II, Ladowski JS, Dillon TA, et al. Chlorhexidine gluconate $0.12 \%$ oral rinse reduces the incidence of total nosocomial respiratory infection and nonprophylactic systemic antibiotic use in patients undergoing heart surgery. Chest. 1996;109: $1556-1561$.

56. Valles J, Artigas A, Rello J, et al. Continuous aspiration of subglottic secretions in preventing ventilator-associated pneumonia. Ann Intern Med. 1995;122:179-186.

57. Heyland DK, Drover JW, MacDonald S, et al. Effect of postpyloric feeding on gastroesophageal regurgitation and pulmonary microaspiration: results of a randomized controlled trial. Crit Care Med. 2001;29:1495-1501.

58. Heyland DK, Drover JW, Dhaliwal R, et al. Optimizing the benefits and minimizing the risks of enteral nutrition in the critically ill: role of small bowel feeding. J Parenter Enteral Nutr. 2002; 26(suppl 6):S51-S55; discussion S56-S57.

59. Marik PE, Zaloga GP. Gastric versus post-pyloric feeding: a systematic review. Crit Care. 2003;7:R46-R51. Epub May 6, 2003.

60. Marcuard SP, Stegall KL, Trogdon S. Clearing obstructed feeding tubes. J Parenter Enteral Nutr. 1989;13:81-83. 